\title{
CFD simulation of non-isothermal mixing ventilation in a generic enclosure: impact of computational and physical parameters
}

\author{
Katarina Kosutova $^{1 *}$, Twan van Hooff ${ }^{1,2}$, Bert Blocken ${ }^{1,2}$ \\ ${ }^{1}$ Building Physics and Services, Department of the Built Environment, Eindhoven University \\ of Technology, P.O. box 513, 5600 MB Eindhoven, the Netherlands \\ ${ }^{2}$ Building Physics Section, Department of Civil Engineering, KU Leuven, Kasteelpark \\ Arenberg 40 - bus 2447, 3001 Leuven, Belgium \\ * Corresponding author: k.kosutova@tue.nl
}

\begin{abstract}
Ventilation is required to provide a healthy and comfortable indoor environment for building occupants. However, proper design of ventilation strategies requires detailed information about the indoor airflow, which can be obtained using computational fluid dynamics (CFD) simulations. CFD simulations have to be performed with the utmost care, as they are very sensitive to the chosen approach and computational and physical parameters imposed. This paper presents a systematic analysis of the impact of computational and physical parameters on non-isothermal mixing ventilation in an enclosure with a heated floor. The results from CFD simulations are validated with experimental data from literature. Six computational and physical parameters are tested: (1) computational grid resolution, (2) Reynolds-averaged Navier-Stokes (RANS) turbulence models, (3) inlet velocity, (4) inlet turbulent kinetic energy, (5) near-wall treatment, and (6) discretization schemes. It is shown that indoor velocities are more sensitive to the change of computational and physical parameters compared to air temperatures and that none of the five tested RANS turbulence models clearly outperforms the other models for both velocities and temperatures. The largest influence on the results is observed for the prediction of mean velocity using different types of near-wall treatment. In addition, if the inlet velocity is decreased by $25 \%$ and $50 \%$, the direction of the recirculation cell changes from clockwise to counter-clockwise.
\end{abstract}

\section{Keywords}

Mixing ventilation, CFD simulation, sensitivity study, airflow, temperature distribution 


\begin{tabular}{|c|c|c|}
\hline \multicolumn{3}{|c|}{ Nomenclature } \\
\hline \multicolumn{3}{|l|}{$\begin{array}{l}\text { Roman } \\
\text { symbols }\end{array}$} \\
\hline$|\mathrm{V}|$ & Velocity magnitude & {$[\mathrm{m} / \mathrm{s}]$} \\
\hline $\mathrm{D}_{\mathrm{h}}$ & Hydraulic diameter & {$[\mathrm{m}]$} \\
\hline g & Gravitational acceleration & {$\left[\mathrm{m} / \mathrm{s}^{2}\right]$} \\
\hline $\mathrm{H}$ & Height of the enclosure & {$[\mathrm{m}]$} \\
\hline $\mathrm{h}_{\text {in }}$ & Inlet height & {$[\mathrm{m}]$} \\
\hline I & Turbulence intensity & {$[\%]$} \\
\hline $\mathrm{k}$ & Turbulent kinetic energy & {$\left[\mathrm{m}^{2} / \mathrm{s}^{2}\right]$} \\
\hline $\mathrm{L}$ & Length of the enclosure & {$[\mathrm{m}]$} \\
\hline $\mathrm{O}$ & Observed value & {$\left[{ }^{\circ} \mathrm{C}\right.$ or $\left.\mathrm{m} / \mathrm{s}\right]$} \\
\hline $\mathrm{P}$ & Predicted value & {$\left[{ }^{\circ} \mathrm{C}\right.$ or $\left.\mathrm{m} / \mathrm{s}\right]$} \\
\hline $\mathrm{T}$ & Temperature & {$\left[{ }^{\circ} \mathrm{C}\right]$} \\
\hline $\mathrm{T}_{\mathrm{fl}}$ & Floor temperature & {$\left[{ }^{\circ} \mathrm{C}\right]$} \\
\hline $\mathrm{T}_{\text {in }}$ & Inlet temperature & {$\left[{ }^{\circ} \mathrm{C}\right]$} \\
\hline $\mathrm{T}_{\mathrm{w}}$ & Wall temperature & {$\left[{ }^{\circ} \mathrm{C}\right]$} \\
\hline $\mathrm{U}$ & Streamwise velocity & {$[\mathrm{m} / \mathrm{s}]$} \\
\hline $\mathrm{U}_{\text {in }}$ & Inlet velocity & {$[\mathrm{m} / \mathrm{s}]$} \\
\hline $\mathrm{U}_{\text {ref }}$ & Reference velocity & {$[\mathrm{m} / \mathrm{s}]$} \\
\hline V & Vertical velocity & {$[\mathrm{m} / \mathrm{s}]$} \\
\hline $\mathrm{y}^{*}$ & Dimensionless wall distance & {$[-]$} \\
\hline \multicolumn{3}{|c|}{ Greek symbols } \\
\hline$\beta$ & Thermal expansion coefficient & {$[1 / \mathrm{K}]$} \\
\hline$\varepsilon$ & Turbulence dissipation rate & {$\left[\mathrm{m}^{2} / \mathrm{s}^{3}\right]$} \\
\hline$v$ & Kinematic viscosity & {$\left[\mathrm{m}^{2} / \mathrm{s}\right]$} \\
\hline$\omega$ & Specific dissipation rate & {$[1 / \mathrm{s}]$} \\
\hline \multicolumn{3}{|c|}{ Dimensionless numbers } \\
\hline $\mathrm{Fr}$ & Froude number & \\
\hline Gr & Grashof number & \\
\hline $\mathrm{Pe}$ & Peclet number & \\
\hline $\operatorname{Pr}$ & Prandtl number & \\
\hline $\operatorname{Re}$ & Reynolds number & \\
\hline $\mathrm{Ri}$ & Richardson number & \\
\hline \multicolumn{3}{|c|}{ Acronyms } \\
\hline CFD & Computational fluid dynamics & \\
\hline FAC1.05 & Factor of 1.05 observations & \\
\hline
\end{tabular}




\begin{tabular}{|ll|} 
FAC1.25 & Factor of 1.25 observations \\
FB & Fractional bias \\
LR & Large eddy simulation \\
LRNM & Low-Reynolds \\
MUSCL & Low-Reynolds number modeling \\
QUICK & Monotonic upwind scheme for conservation laws \\
RANS & Quadratic upstream interpolation for convective kinematics \\
RNG & Reynolds-averaged Navier-Stokes \\
RSM & Renormalization group \\
SIMPLE & Reynolds stress model \\
SST & Semi implicit method for pressure linked equations \\
ST & Shear-stress transport \\
TKE & Standard \\
WF & Turbulent kinetic energy \\
WT & Wall function \\
\hline
\end{tabular}




\section{Introduction}

Ventilation is required to provide a healthy and comfortable indoor environment for the occupants of buildings. In particular, natural ventilation can be used as a sustainable and energy-efficient solution to reduce indoor temperature and thus decrease the cooling energy demand of buildings. However, a proper design of ventilation strategies, whether mechanical or natural, requires detailed information about the velocity and temperature distribution in the enclosure, which is not straightforward. Indoor airflow is complicated due to the combination of free stream flow, near-wall effects, the presence of separation and reattachment zones and the presence of thermal effects.

In the past, a lot of research focused on modeling ventilation and evaluating its performance either by experimental (e.g. [1-9]), analytical (e.g. [7]) or computational methods (e.g. [1, 5, 921],). A considerable amount of studies concerning indoor airflow was carried out using computational fluid dynamics (CFD) (e.g. [5, 9-36]). However, in CFD the accuracy and reliability of the solution strongly relies on the chosen approach, boundary conditions and computational settings. The vast majority of ventilation studies were performed using Reynolds-averaged Navier-Stokes (RANS) simulations, although it is recognized that for some cases large eddy simulations (LES) can provide more accurate results (e.g. [30-32]). However, the grid requirements and computational costs associated with LES are considerably higher than for RANS, which is why the RANS approach is still most often used. When performing RANS simulations, a proper turbulence model is necessary to provide closure to the governing equations. Its ability to correctly reproduce the turbulence quantities and its influence on the mean velocities and heat transfer processes is of great importance concerning the accuracy of the simulation results, therefore, validation of turbulence models for indoor airflow is imperative. Several researchers performed validation of turbulence models for indoor airflow under isothermal (e.g. [13, 27, 32-34]) or non-isothermal conditions (e.g. [16, 21, 25-26, 29, $31,35])$.

Some studies considered non-isothermal mixing ventilation flows. For example, Chen [35] investigated five different $\mathrm{k}-\varepsilon$ turbulence models (standard k- $\varepsilon$ model, a low Reynolds (LR) k$\varepsilon$ model, a two-layer k- $\varepsilon$ model, a two-scale k- $\varepsilon$ model and a renormalization group (RNG) k- $\varepsilon$ model) for the prediction of airflow and convective heat transfer in a $2 \mathrm{D}$ enclosure. He concluded that overall these models were able to predict the mean velocity fairly well but they performed poorly in predicting turbulent kinetic energy. The RNG k- $\varepsilon$ model emerged as the best model for simulation of indoor airflow among the tested $k-\varepsilon$ turbulence models, however, it was also noted that all k- $\varepsilon$ models failed to predict the anisotropic turbulence of the airflow in this particular case [35]. In addition, Chen [25] studied the prediction of indoor airflow by Reynolds-stress models (RSM) (two with isotropization of production assumption and a quasiisotropic model) and the standard k- $\varepsilon$ model for natural, forced and mixed convection in a 2D enclosure. For forced convection, which in this case represented mixing ventilation, all RSM models showed a better performance than the standard k- $\varepsilon$ model; however, the improvement was not significant [25]. In addition, the better performance of RSM over the k- $\varepsilon$ based models was also confirmed by a mixing ventilation study of Moureh and Flick [36], in which the RNG $\mathrm{k}-\varepsilon$ model failed to predict any separation of the flow, while the RSM correctly predicted separation of the flow as well as the secondary recirculation vortex.

Costa et al. [16] investigated the performance of eight low-Reynolds (LR) number versions of the k- $\varepsilon$ model and one high-Reynolds k- $\varepsilon$ model by Chieng and Launder [37] for 2D nonisothermal indoor mixed convection flow. The LR number versions of the k- $\varepsilon$ model solve the same two transport equations ( $\mathrm{k}$ and $\varepsilon$ ) in the near-wall region as in the fully turbulent region, however, they use damping functions to take into account the reduced levels of turbulent viscosity close to the wall, while the high-Reynolds number versions either bridge the nearwall region using wall functions or use the two-layer model with the one-equation Wolfshtein model [38] for the viscosity affected region (low-Reynolds number modeling of the near-wall flow), depending on the employed near-wall grid resolution. The authors reported that all the models qualitatively reproduced the main features of the flow and overall the best performance was achieved with the LR k- $\varepsilon$ model by Nagano and Hishida [39] followed by the high-Re k- $\varepsilon$ 
model, which actually outperformed all of the other LR k- $\varepsilon$ models.

As expected, the conclusions on which turbulence model is the best for predicting indoor airflows are not always in line with each other. While some studies that focused on nonisothermal airflow concluded that the RNG k- $\varepsilon$ model provided the best agreement with the experimental results (e.g. [35]), other studies suggested that the best results can be obtained with RSM (e.g. $[15,25]$ ), which can correctly predict main features of the airflow as well as secondary vortices. Although it is known that the performance of RSM is potentially superior due to the inclusion of transport equations for each of the six individual Reynolds stresses (e.g ref. [40]), it is also associated with higher computational costs and less straightforward convergence (e.g. [25]).

Whilst all abovementioned studies concentrated solely on turbulence model validation, few studies considered the influence of different geometrical or thermal parameters on the flow structure. Costa et al. [17] performed a parametric study varying the length of the enclosure, width of the inlet slot, wall temperatures and the ratio of inertia to buoyancy forces. The authors concluded that in case of fixed airflow rates it is possible to find an optimal width of the inlet jet section allowing a minimum velocity of the return flow. In addition, they reported complete flow reversal in case of low jet momentum in combination with significant temperature differences between the temperature of the inlet air and walls. Flow reversal was also reported by Ezzouhri et al. [41] in their LES study of turbulent mixed convection in a 3D cavity where flow bifurcation was characterized by a critical Froude number.

Although a couple of parametric studies on non-isothermal mixing ventilation were published (e.g. $[16-17,21])$, to the best knowledge of the authors, a comprehensive sensitivity study assessing the influence of computational and physical parameters on the simulation results for non-isothermal mixing ventilation has not yet been performed.

The objective of this study is to assess the accuracy of 3D steady-state RANS simulations for non-isothermal mixing ventilation flow in a generic enclosure. The study focuses on the impact of six computational and physical parameters on the simulation results: computational grid resolution (Section 4.1), turbulence models (Section 4.2), inlet velocity (Section 4.3), inlet turbulent kinetic energy (Section 4.4), near-wall treatment (Section 4.5) and spatial discretization schemes (Section 4.6).

Section 2 provides an overview of the experimental results used for the validation study. The CFD simulations for the reference case (including validation study) are presented in Section 3. Section 4 presents the results of the parametric study. The paper is concluded with Discussion (Section 5) and Conclusions (Section 6).

\section{Experimental setup}

Laboratory experiments were performed by Blay et al. [42] to analyze the non-isothermal flow in a slot-ventilated enclosure. The experiments were performed in a cavity with dimensions $1040 \times 1040 \times 700 \mathrm{~mm}^{3}(\mathrm{D} \times \mathrm{H} \times \mathrm{W})$ equipped with an $18 \mathrm{~mm}$ high linear inlet slot $\left(\mathrm{h}_{\text {in }}\right)$ and a $24 \mathrm{~mm}$ high linear outlet slot $\left(\mathrm{h}_{\text {out }}\right)$ located in the wall opposite to the inlet. The cavity was divided by transparent double glazed walls into three smaller cavities: one central working cavity (width $300 \mathrm{~mm}$ ) where the measurements were performed, and two guard cavities (each of them $200 \mathrm{~mm}$ wide) where the same flow as in the working cavity was reproduced (Fig. 1b). Dividing the cavity into three parts ensured a fairly good two-dimensional flow in the central cavity by eliminating thermal effects between the working cavity and its surroundings [42]. A fixed wall temperature of $15^{\circ} \mathrm{C}$ was imposed at the four active walls (Fig. 1b), which were made of flat aluminum heat exchangers and maintained at a constant and uniform temperature using a temperature controlled water system [42]. The floor of the enclosure was heated to $35.5^{\circ} \mathrm{C}$. In order to ensure a uniform velocity over the width and height of the inlet, screens and honeycombs were positioned upstream of the inlet. The supply air was cooled down using a water-air heat exchanger where the water was controlled by a cryothermostat with a precision of $0.25^{\circ} \mathrm{C}$ and was supplied to the enclosure with a velocity of $0.57 \mathrm{~m} / \mathrm{s}$ and a temperature of $15^{\circ} \mathrm{C}$. Turbulence intensity measured at the inlet was $6 \%$. Time-averaged velocities and 
turbulent fluctuations were measured when the indoor conditions reached a statistically steady state. They were obtained using a two-color laser Doppler velocimetry device. The temperature measurements were performed with a $20 \mu \mathrm{m} \mathrm{Cr}-\mathrm{Al}$ thermocouple [42].
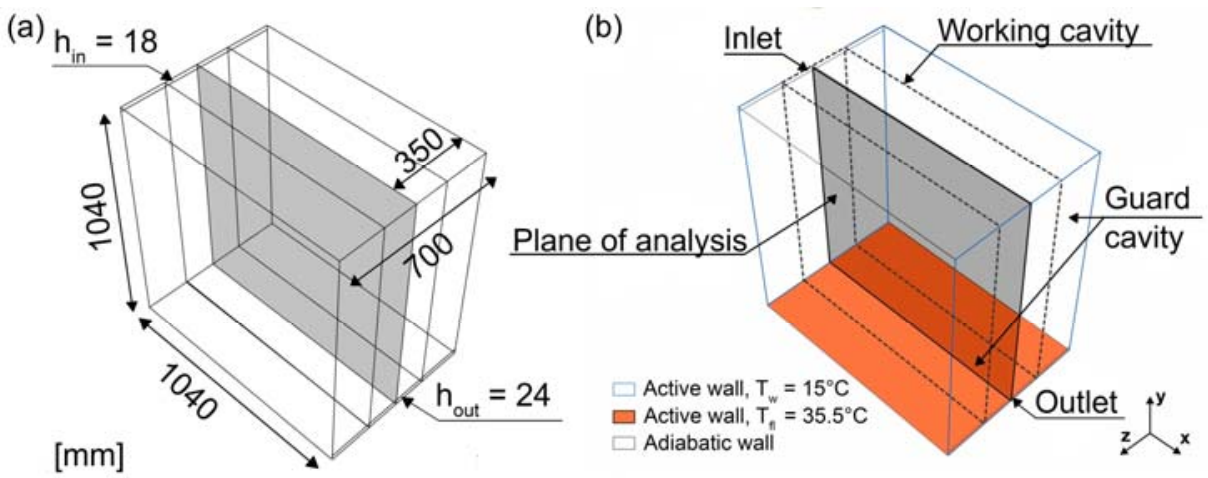

Figure 1: Geometry of the enclosure: (a) dimensions in mm; (b) division of the enclosure.

\section{CFD simulations: reference case}

\subsection{Computational domain and grid}

The computational domain is created only for the working cavity; the guard cavities are excluded and their effect is reproduced by making the two side walls (without inlet and outlet) of the domain adiabatic (Fig. 2a). The fully structured hexahedral computational grid is created using the surface grid-extrusion technique by van Hooff and Blocken [12], which allows full control of the quality of each grid cell. First, a 2D grid for a vertical plane is created which is subsequently extended in the third dimension. The grid contains 25,704 cells and is illustrated in Figure 2b. A finer grid is applied in the boundary layer for a detailed prediction of the large velocity gradients and surface-to-air heat transfer. In addition, a higher grid resolution is applied in the shear layer of the incoming jet. The dimensionless wall distance $\left(\mathrm{y}^{*}\right)$ is lower than 5 in order to allow the use of low-Reynolds number modelling (LRNM), which means resolving the flow all the way down to the viscous sublayer and which increases the prediction accuracy of convective heat transfer from the heated floor to the air inside the enclosure. This is important as the largest resistance to convective heat transfer is present in this thin viscous sublayer.

(a)

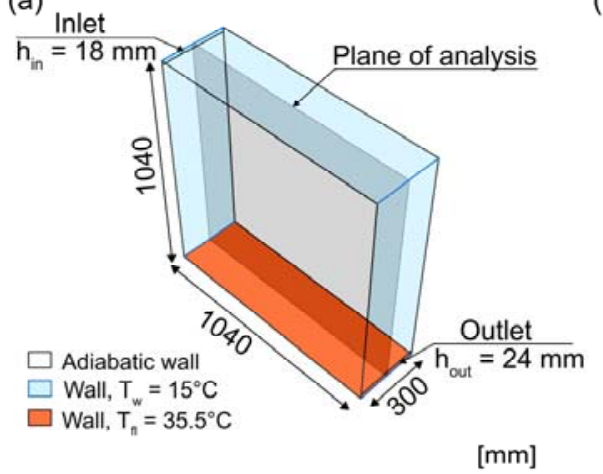

(b)

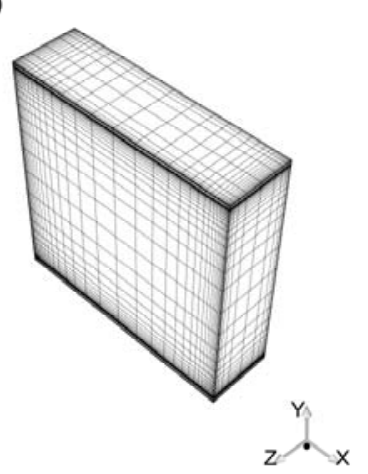

Figure 2: Computational model of the enclosure used for the CFD simulations; (a) scheme of the model indicating boundary conditions imposed on the walls of the model; (b) computational grid (25,704 cells). All dimensions are in $\mathrm{mm}$. 


\subsection{Boundary conditions}

The boundary conditions for the CFD simulations are chosen to reproduce the boundary conditions used in the experiment as much as possible. The top wall and the walls in which the inlet and outlet are situated are maintained at a fixed surface temperature equal to the temperature of the inlet air: $\mathrm{T}_{\text {wall }}=\mathrm{T}_{\text {in }}=15^{\circ} \mathrm{C}$. All walls are modeled as smooth no-slip walls. The floor temperature $\left(\mathrm{T}_{\mathrm{fl}}\right)$ is set to $35.5^{\circ} \mathrm{C}$. The two side walls are considered to be adiabatic; i.e. zero heat flux condition. A uniform velocity of $0.57 \mathrm{~m} / \mathrm{s}$ is imposed at the inlet $\left(U_{\text {in }}\right)$. The corresponding Reynolds number $\mathrm{Re}=\left(\mathrm{U}_{\mathrm{in}} \mathrm{h}_{\mathrm{in}}\right) / v$, with $v$ the kinematic viscosity, and the horizontal jet Froude number $\mathrm{Fr}=\mathrm{U}_{\mathrm{in}} / \sqrt{ }\left(\mathrm{g} \beta \mathrm{L}\left(\mathrm{T}_{\mathrm{fl}}-\mathrm{T}_{\mathrm{in}}\right)\right)$, with $\mathrm{g}$ the gravitational acceleration and $\beta$ the thermal expansion coefficient, are equal to $\mathrm{Re}=684$ and $\mathrm{Fr}=5.31$, respectively. The Richardson number (Ri) can be calculated based on the Grashof and Reynolds number: $\mathrm{Gr} / \mathrm{Re}^{2}$ with $\mathrm{Gr}=\left(\mathrm{gL}^{3} \beta\left(\mathrm{T}_{\mathrm{fl}}-\mathrm{T}_{\mathrm{in}}\right)\right) / v^{2}$. The Richardson number determines the importance of buoyancy forces in mixed convention flow and is equal to $\mathrm{Ri}=0.038$ for this case, indicating that buoyancy effects on the airflow pattern are limited. The turbulence parameters are specified using the turbulence intensity (I) and the hydraulic diameter $\left(D_{h}\right)$. The level of turbulence intensity, $\mathrm{I}=6 \%$, corresponds to the measured value [42]. The hydraulic diameter, $\mathrm{D}_{\mathrm{h}}=0.035$ $\mathrm{m}$, is calculated using Eq. (1):

$$
D_{h}=(4 W H) /(2(W+H))
$$

with $\mathrm{W}$ the width and $\mathrm{H}$ the height of the inlet $\left(=\mathrm{h}_{\text {in }}\right)$. Zero static gauge pressure is imposed at the outlet.

\subsection{Solver settings}

The commercial CFD code ANSYS Fluent 15 [43] is used to perform the simulations. In the reference case, the 3D steady RANS equations are solved together with the RNG k- $\varepsilon$ turbulence model to provide closure and in combination with low-Reynolds number modeling (LRNM) as near-wall treatment. Steady RANS is a commonly used approach to model indoor airflow despite its transient nature (e.g. [11-22,25,29,33-36]). Although RANS has some shortcomings, it can reproduce indoor airflow with reasonable accuracy. For example, van Hooff et al. [13] showed that steady RANS can predict indoor airflow in an enclosure also for transitional slot $\operatorname{Re}$ numbers $(\operatorname{Re} \approx 1000$ and $\operatorname{Re} \approx 2500)$. LES can provide slightly more precise results but at much higher computational costs. The potential improvement in accuracy of the results obtained by LES over RANS is not always large enough to justify the very large increase in computation time (e.g. [30]).

The RNG k- $\varepsilon$ turbulence model by Yakhot [44] is an improved version of the standard k- $\varepsilon$ model and it is widely used for the CFD simulations of indoor airflow (e.g. [35,45-47]).

The SIMPLE algorithm is a guess-and-correct iterative procedure for calculating pressure and it is commonly used for pressure-velocity coupling for simulating indoor airflow in enclosures (e.g. [46]). Second-order discretization schemes for both the convective and the viscous terms of the governing equations as well as for pressure interpolation are chosen based on the best practice guidelines (e.g. [22, 48-50]). The use of second-order discretization schemes is favored over first-order discretization schemes due to their much less diffusive character. The Boussinesq approximation is used for buoyancy, which is justified since $\beta\left(T_{\mathrm{fl}}-\mathrm{T}_{\mathrm{in}}\right)=0.07<<1$, where $T_{\mathrm{fl}}-\mathrm{T}_{\mathrm{inf}}$ is the maximum occurring temperature difference (e.g. [43]). Radiative heat transfer was not modelled, in line with the experimental setup that was designed to remove the effects of radiation: "Radiative heat transfer between wall surfaces and conductive heat transfer within the walls were not taken into consideration thanks to imposed temperature conditions on the four active walls as boundary conditions. The two other transparent walls separating the central cavity were considered to be adiabatic" [42]. The latter statement points to the presence of the two guard cavities. Convergence is assumed to be obtained when all the residuals level off. The scaled residuals reach minimum values of $10^{-5}$ for continuity, turbulent dissipation rate, turbulent kinetic energy and for $\mathrm{x}-, \mathrm{y}-$ and $\mathrm{z}^{-}$velocity and $10^{-8}$ for energy. Oscillatory convergence is observed, which implies that it is not possible to reach a unique converged 
solution, and that the solution depends on the number of iterations after which the simulation is terminated. This can occur when an inherently transient flow is forced to be predicted by steady RANS simulations [50]. Ramponi and Blocken [33] showed that accurate simulation results could be obtained when oscillatory convergence is present, however, the results need to be averaged over at least a period of oscillatory behavior [50]. Therefore, the variables are calculated by averaging over 1,800 iterations in order to obtain a statistically steady solution.

\subsection{Validation with experimental results}

The CFD results for the reference case are compared with the experimental results by Blay et al. [42] in terms of dimensionless mean streamwise $\left(\mathrm{U} / \mathrm{U}_{\text {in }}\right)$ and vertical velocities $\left(\mathrm{V} / \mathrm{U}_{\text {in }}\right)$ and air temperatures $\left(\left(\mathrm{T}-\mathrm{T}_{\text {in }}\right) / \mathrm{T}_{\text {in }}\right)$ along the horizontal $(\mathrm{y} / \mathrm{L}=0.5)$ and vertical $(\mathrm{x} / \mathrm{L}=0.5)$ centerline. Note that $\mathrm{L}$ is equal to the depth (D) and height $(\mathrm{H})$ of the cavity; both of which are $1040 \mathrm{~mm}$. Figure 3 shows a very good agreement of predicted velocities and temperatures with experimental results. CFD slightly underpredicts $\left(\mathrm{T}-\mathrm{T}_{\mathrm{in}}\right) / \mathrm{T}_{\text {in }}$ along both the horizontal and vertical centerline (Fig. 3c,d). Note that error bars are plotted to indicate the measurement accuracy, which is obtained from Blay et al. [42].

a)
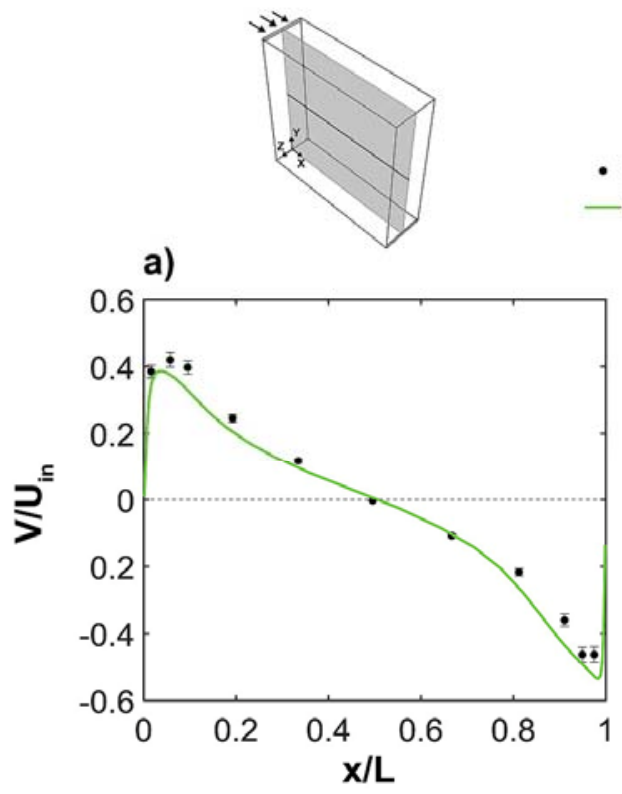

c)

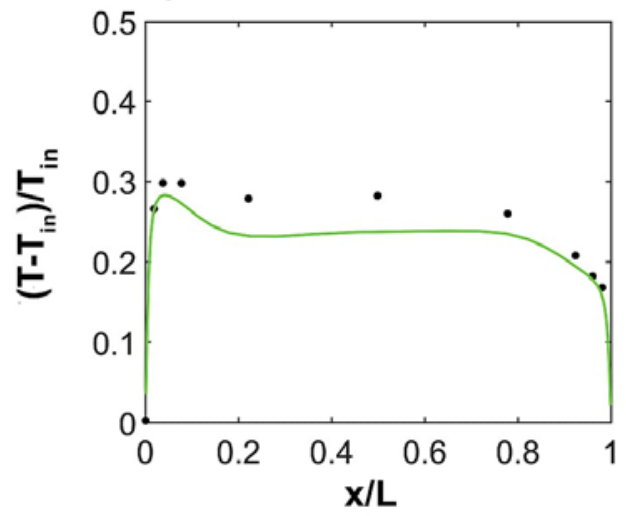

b)

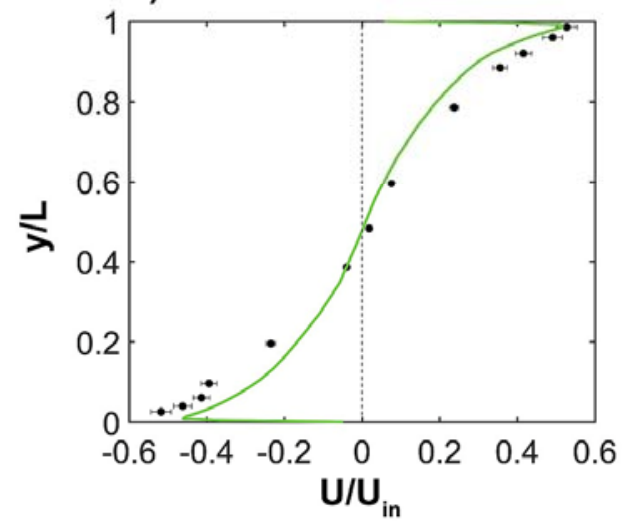

d)

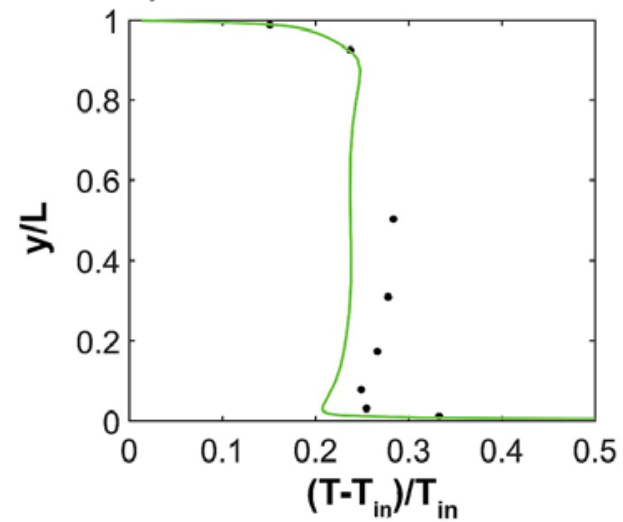

Figure 3: Comparison of CFD results with the experimental data from literature [42]. (a,b) $V / U_{\text {in }}$ and $U / U_{\text {in }}$ along: (a) horizontal centerline; (b) vertical centerline. (c,d) $\left(T-T_{\text {in }}\right) / T_{\text {in }}$ along: (c) horizontal centerline; (d) vertical centerline. 
A quantitative comparison between the results obtained from CFD and the experimental results is performed as well. The fractional bias (FB) (Eq. 2) and the fraction of data within a factor of 1.25 (i.e. FAC1.25 for velocities; Eq. 3) and within a factor of 1.05 (i.e. FAC1.05 for temperatures; Eq. 4) are used to quantify the agreement.

$$
\begin{gathered}
F B=\frac{\bar{O}-\bar{P}}{0.5(\bar{O}+\bar{P})} \\
F A C 1.25=\frac{1}{N} \sum_{i=1}^{N} n_{i} \text { with } n_{i}=\left\{\begin{array}{c}
1 \text { for } 0.80 \leq \frac{P_{i}}{O_{i}} \leq 1.25 \\
0 \text { else }
\end{array}\right\} \\
\text { FAC } 1.05=\frac{1}{N} \sum_{i=1}^{N} n_{i} \text { with } n_{i}=\left\{\begin{array}{c}
1 \text { for } 0.95 \leq \frac{P_{i}}{O_{i}} \leq 1.05 \\
0 \text { else }
\end{array}\right\}
\end{gathered}
$$

In these equations, $\mathrm{O}$ corresponds to the observed (measured) values and $\mathrm{P}$ corresponds to predicted (computed) values. The overbar denotes averaging over all data points. Please note that FB is not suitable for parameters which can take both positive and negative values, therefore it is only used for temperature [51].

The good agreement between the CFD results and the experimental results is confirmed by the validation metrics shown in Table 1. FAC1.25 is above the acceptance limit of 0.5 for the mean velocities along both centerlines. In fact, for the mean velocity on the horizontal centerline $\left(\mathrm{V} / \mathrm{U}_{\text {in }}\right)$ FAC1.25 is very close to the aimed value $(=1)$. For temperatures, FAC1.05 is very close to the aimed value along both centerlines and FB also indicates a very good agreement between experimental and numerical results along both centerlines.

Table 1: Validation metrics for the reference case.

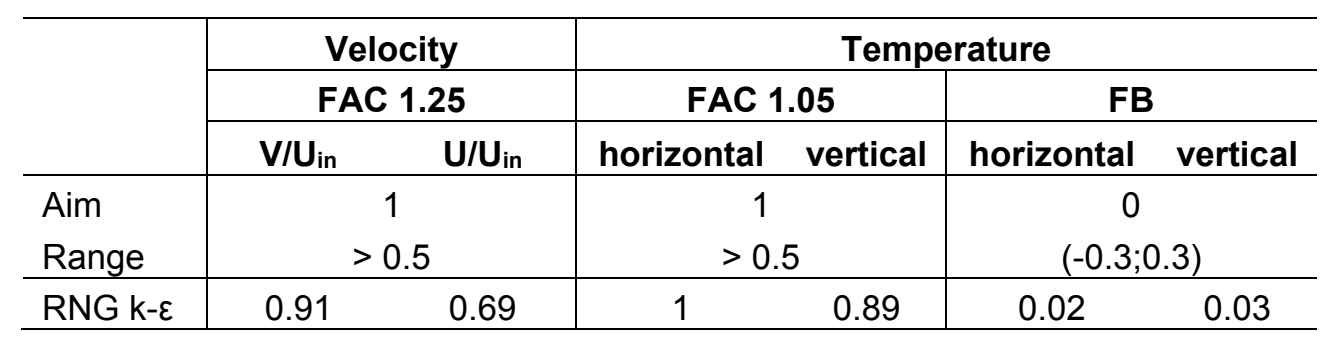

\section{CFD simulations: impact of computational and physical parameters}

A detailed and systematic sensitivity analysis is carried out for the reference case by varying one parameter at a time and evaluating its impact on the simulation results. The following parameters are tested: computational grid resolution (Section 4.1), turbulence models (Section 4.2), inlet velocity (Section 4.3), inlet turbulent kinetic energy (Section 4.4), wall treatment (Section 4.5) and spatial discretization schemes (Section 4.6). Table 2 provides an overview of the computational and physical parameters used for the sensitivity analysis. 
Table 2: Overview of computational and physical parameters used for the sensitivity analysis with an indication of

\begin{tabular}{|c|c|c|c|c|c|}
\hline $\begin{array}{l}\text { Computational } \\
\text { grid } \\
\text { resolution } \\
\text { (Section 4.1) }\end{array}$ & $\begin{array}{l}\text { Turbulence } \\
\text { models } \\
\text { (Section 4.2) }\end{array}$ & $\begin{array}{l}\text { Inlet velocity } \\
{[\mathrm{m} / \mathrm{s}]} \\
\text { (Section } 4.3 \text { ) }\end{array}$ & $\begin{array}{l}\text { Inlet turbulent kinetic } \\
\text { energy } \times 10^{-3}\left[\mathrm{~m}^{2} / \mathrm{s}^{2}\right] \\
(\text { Section } 4.4)\end{array}$ & $\begin{array}{l}\text { Wall treatment } \\
\text { (Section 4.5) }\end{array}$ & $\begin{array}{l}\text { Discretization } \\
\text { schemes } \\
\text { (Section 4.6) }\end{array}$ \\
\hline 25,704 & RNG k- $\varepsilon$ & $U_{\text {ref }}=0.57$ & $\mathrm{TKE}_{\text {ref }}=1.25$ & Low-Re modeling & $2^{\text {nd }}$ order \\
\hline 71,000 & LR k- $\varepsilon$ & $0.50 \mathrm{U}_{\text {ref }}=0.29$ & $0.50 \mathrm{TKE}_{\mathrm{ref}}=0.63$ & Standard WF & $\begin{array}{l}1^{\text {st }} \text { order } \\
3^{\text {rd }} \text { order }\end{array}$ \\
\hline \multirow[t]{7}{*}{200,788} & SST k- $\omega$ & $0.75 \mathrm{U}_{\text {ref }}=0.43$ & $0.75 \mathrm{TKE}_{\mathrm{ref}}=0.94$ & Scalable WF & MUSCL \\
\hline & ST k-w & $0.90 U_{\text {ref }}=0.51$ & $0.90 \mathrm{TKE}_{\mathrm{ref}}=1.13$ & & Power law \\
\hline & $\mathrm{RSM}^{*}$ & $0.95 U_{\text {ref }}=0.54$ & $0.95 \mathrm{TKE}_{\mathrm{ref}}=1.19$ & & QUICK \\
\hline & & $1.05 \mathrm{U}_{\text {ref }}=0.60$ & $1.05 \mathrm{TKE}_{\mathrm{ref}}=1.31$ & & \\
\hline & & $1.10 U_{\text {ref }}=0.63$ & $1.10 \mathrm{TKE}_{\mathrm{ref}}=1.38$ & & \\
\hline & & $1.25 \mathrm{U}_{\text {ref }}=0.71$ & $1.25 \mathrm{TKE}_{\mathrm{ref}}=1.56$ & & \\
\hline & & $1.50 U_{\text {ref }}=0.86$ & $1.50 \mathrm{TKE}_{\mathrm{ref}}=1.88$ & & \\
\hline
\end{tabular}

${ }^{*}$ Linear pressure strain model [57].

\subsection{Impact of computational grid resolution}

A grid-sensitivity analysis is important in terms of minimizing discretization errors and saving computational time and should be included in every CFD study. Although a grid-sensitivity analysis is imperative in CFD studies it is not always performed and the computational grid resolution can thus be regarded as a computational parameter that can influence the results when randomly constructed. Overall, a systematic grid refinement with a constant factor is recommended in all three directions in order to obtain grid-independent or nearly gridindependent results (e.g. [50, 51, 52]). However, when choosing a grid-refinement factor, a compromise has to be made between sufficiently coarsened/refined grid and computational time (especially with regards to the refined grid). The grid-refinement factor is therefore chosen based on these criteria and based on previous studies conducted for similar geometries, e.g van Hooff et al. [13] and based on best practice guidelines by Blocken et al. [50], Roache [51,52], Ferziger and Peric [53], Franke et al. [54] and Tominaga et al. [55].

Two additional computational grids are constructed by refining the reference grid with a factor of $\sqrt{ } 2$ in all three directions. This results in three computational grids in total: fine grid $(200,788$ cells), basic grid (71,000 cells) and coarse (reference) grid (25,704 cells). The number of cells over the inlet is 25,18 and 13 , for the fine, basic and reference grid, respectively. Over the outlet height, 34 cells are used for the fine grid, 24 cells for basic grid and 16 cells for the coarse grid. Values of maximum and average dimensionless wall distance $\left(\mathrm{y}^{*}\right)$ measured along the centerline of the ceiling $(\mathrm{y} / \mathrm{L}=1)$ are shown in Table 3 . The computational grids used for the grid-sensitivity analysis are shown in Figure 4. Figure 5a,b shows the results for $\mathrm{V} / \mathrm{U}_{\text {in }}$ and $\mathrm{U} / \mathrm{U}_{\text {in }}$ along the horizontal $(\mathrm{y} / \mathrm{L}=0.5)$ and vertical $(\mathrm{x} / \mathrm{L}=0.5)$ centerline $(\mathrm{z} / \mathrm{L}=0.5)$. The results obtained from all three grids are almost overlapping along both lines. The differences between the grids are negligible $(<2.6 \%)$. In case of $\left(T-T_{i n}\right) / T_{i n}$, the results obtained from the fine and basic grid overlap, while the reference (coarse) grid shows small differences compared to the other two grids. The average deviation between the reference and the basic grid is $1.1 \%$ along the horizontal centerline and $1.98 \%$ along the vertical centerline; while the average deviation between the reference and fine grid is $1.56 \%$ along the horizontal and $2.5 \%$ along the vertical centerline. Therefore, it can be concluded that the reference grid provides nearly gridindependent results with a large decrease in computational demand and it is therefore used for the remainder of the study. 
Table 3: Maximum and average dimensionless wall distance for all three grids.

\begin{tabular}{c|ccc}
\multicolumn{4}{c}{ Grid } \\
\hline \multicolumn{1}{c|}{$\mathbf{y}^{\boldsymbol{1}}$} & Coarse & Basic & Fine \\
\hline Maximum & 5.1 & 3.4 & 2.8 \\
Average & 1.6 & 1.00 & 0.6 \\
\hline
\end{tabular}

a)

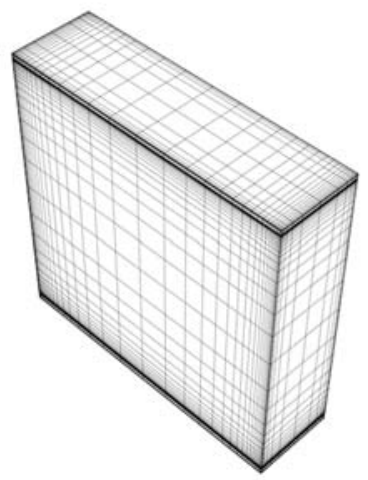

b)

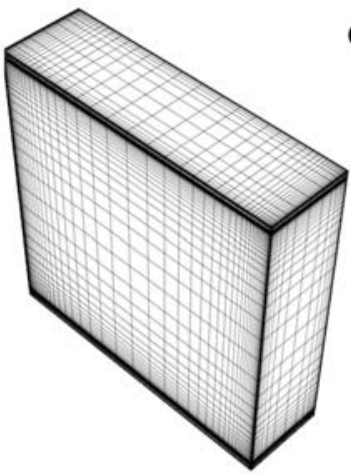

c)

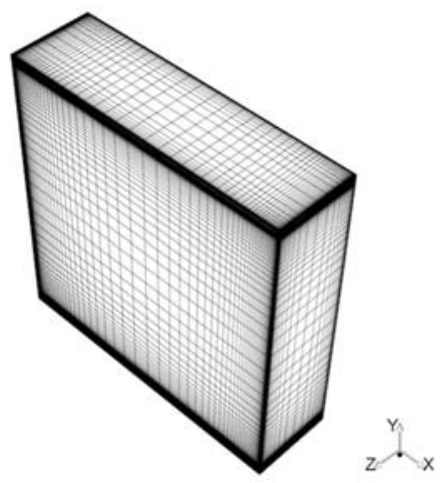

Figure 4: Computational grid used for the grid-sensitivity analysis: (a) coarse grid (25,704 cells); (b) basic grid (71,000 cells); and (c) fine grid (200,788 cells).

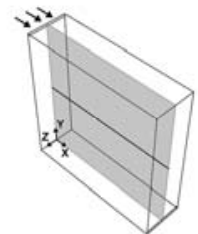

a)

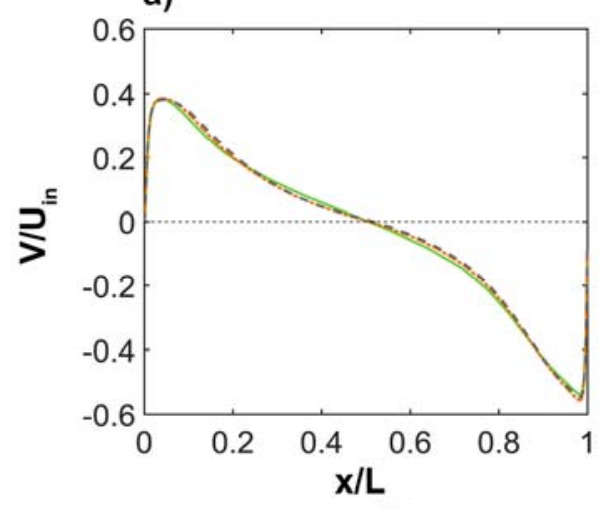

c)

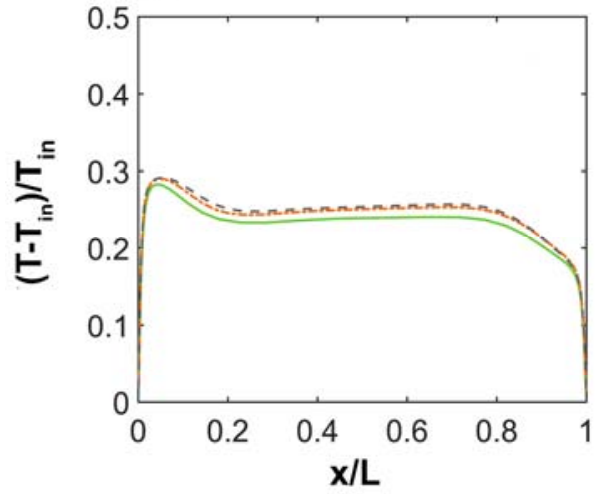

b)

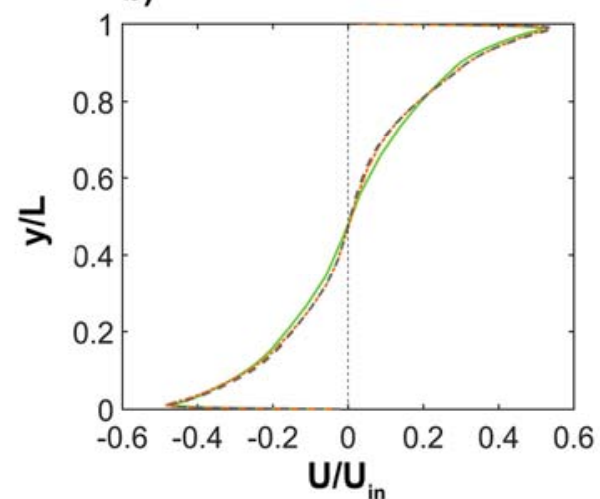

d)

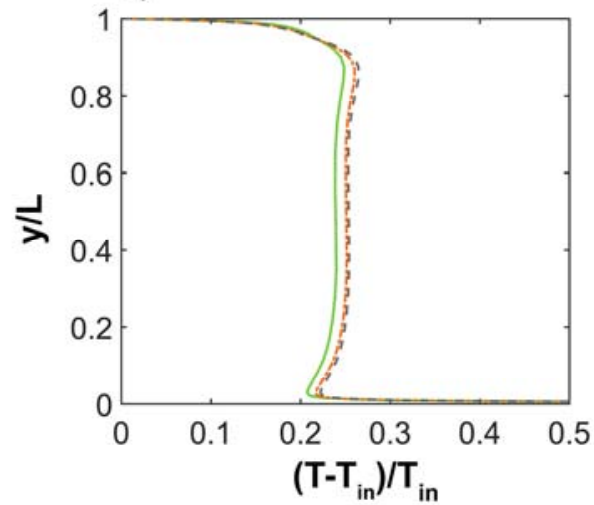

Figure 5: Results from the grid-sensitivity analysis. ( $a, b) V / U_{\text {in }}$ and $U / U_{\text {in }}$ along: (a) horizontal centerline; (b) vertical centerline. $(c, d)\left(T-T_{i n}\right) / T_{\text {in }}$ along: (c) horizontal centerline; (d) vertical centerline. 
Five different RANS turbulence models are assessed; four two-equation eddy-viscosity models: (1) RNG k- $\varepsilon$ model [44]; (2) LR k- $\varepsilon$ model by Abid [58]; (3) shear-stress transport (SST) k- $\omega$ model [59]; (4) standard (ST) k- $\omega$ model [60]; and one second-order closure model; (5) the linear pressure strain RSM model [57]. LR k- $\varepsilon$ includes damping functions to improve its accuracy in the near-wall region. The SST k- $\omega$ model by Menter [59] is a modification of the standard $\mathrm{k}-\omega$ model proposed by Wilcox [60]. SST k- $\omega$ includes a blending function to combine the use of the k- $\omega$ model near the wall region with the k- $\varepsilon$ model far away from the walls. The RSM solves transport equations for all Reynolds stresses and therefore should provide a more accurate calculation of the mean flow and turbulence properties. However, the RSM model is associated with larger computing costs and generally less straightforward convergence (e.g. [25]).

The influence of the turbulence model on the velocities is illustrated in Figure 6. Figure 6a shows a good agreement between the experimental data [42] and V/U in predicted by the LR k$\varepsilon$ and RNG k- $\varepsilon$ models. In the vicinity of the wall, the SST k- $\omega$ model underpredicts $\mathrm{V} / \mathrm{U}_{\text {in }}$ with up to $50 \%$ compared to the experimental results. The difference between the experimental results and RSM is most pronounced at $\mathrm{x} / \mathrm{L}=0.35$ with differences of up to $76 \%$. Figure $6 \mathrm{~b}$ illustrates the comparison of $U / U_{\text {in }}$ along the vertical centerline. The LR $k-\varepsilon$ model provides the closest agreement with the experimental results for prediction of velocity, followed by the RNG $\mathrm{k}-\varepsilon$ model, which shows small discrepancies close to the heated wall. A comparison of (T$\mathrm{T}_{\text {in }} / \mathrm{T}_{\text {in }}$ along the horizontal centerline and vertical centerline is depicted in Figure $6 \mathrm{c}-\mathrm{d}$. The temperature is overpredicted by the LR k- $\varepsilon$ model and underpredicted by the other four turbulence models along both centerlines. 
a)

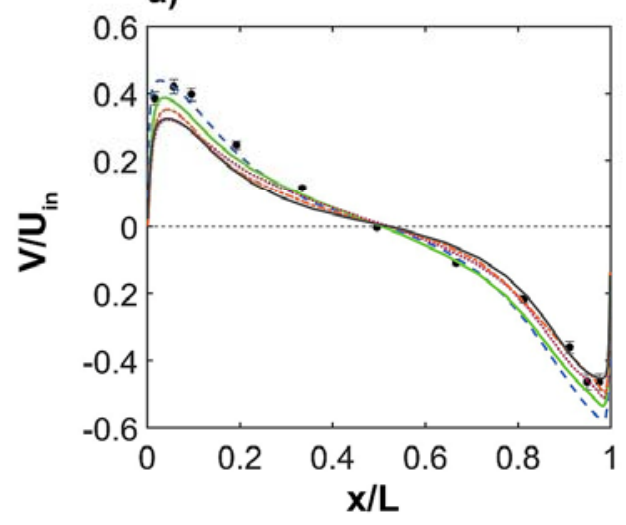

c)

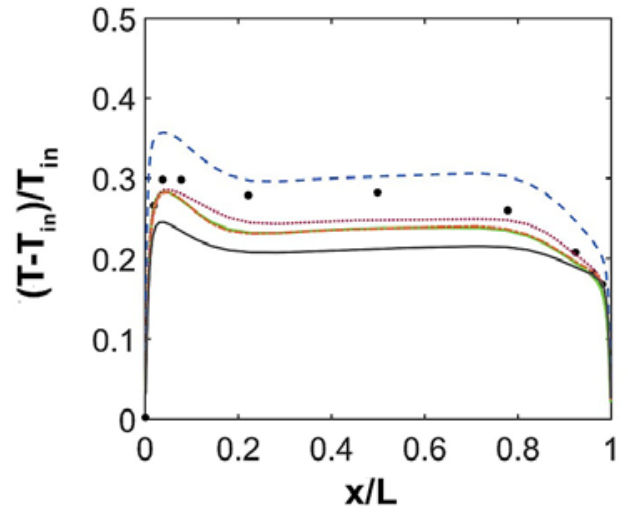

- Exp

- LR k- $\epsilon$

- RNG k- $\epsilon$

-...... SST k- $\omega$

-... St k- $\omega$

- RSM

b)

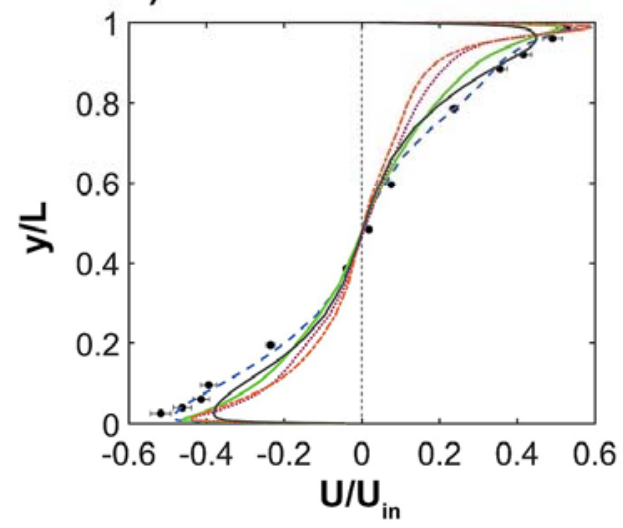

d)

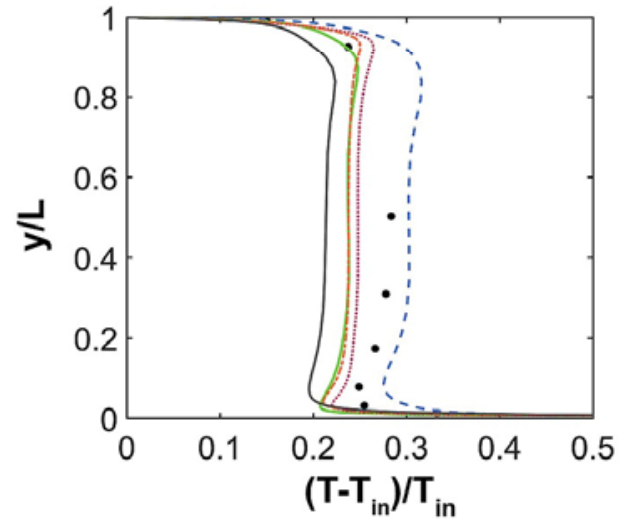

Figure 6: Results from the sensitivity analysis: impact of the turbulence model. (a,b) V/U in and $U / U_{\text {in }}$ along: (a) horizontal centerline; (b) vertical centerline. (c,d) $\left(T-T_{\text {in }}\right) / T_{\text {in }}$ along: (c) horizontal centerline; (d) vertical centerline.

Figure 7 shows contours of the dimensionless velocity magnitude $\left(|\mathrm{V}| / \mathrm{U}_{\text {ref }}\right)$ in the vertical center plane. All models predict flow patterns representative of mixing ventilation, i.e. the inlet jet, jet detachment at the ceiling and a large recirculation cell in the majority of the enclosure. Overall, the RSM predicts the lowest velocities in the regions adjacent to the upstream and downstream wall and the floor. The differences between the five models are visible near the inlet wall (left wall); the jet detaches slightly earlier from the inlet wall with ST k- $\omega$ and RSM than in the rest of the cases, resulting in a larger recirculation cell below the inlet jet in the top left corner of the enclosure. 


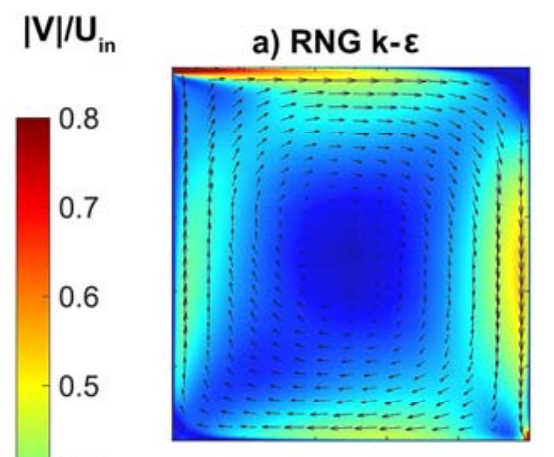

c) SST k-w

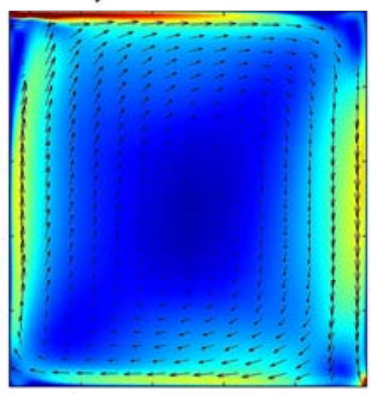

b) LR k- $\varepsilon$

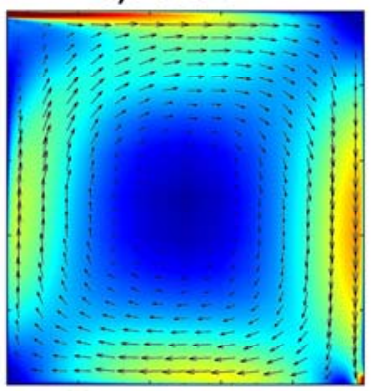

d) ST k-w

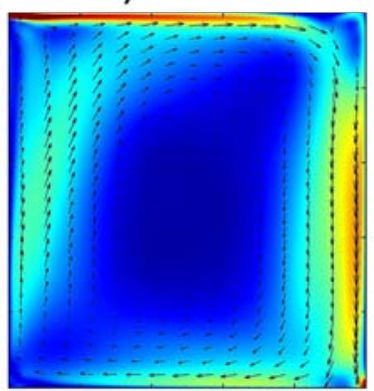

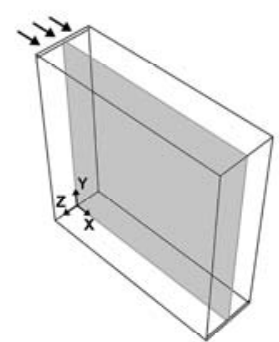

e) RSM

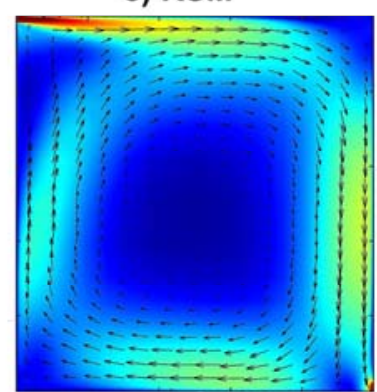

Figure 7: Velocity magnitude in plane of analysis for the turbulence models analyzed: (a) $R N G k-\varepsilon$, (b) $L R k-\varepsilon$, (c) SST k- $\omega$, (d) $S T k-\omega$ and (e) RSM. $U_{r e f}=0.57 \mathrm{~m} / \mathrm{s}$.

The validation metrics summarized in Table 4 confirm that the best prediction of mean velocities is achieved by RNG k- $\varepsilon$ for the horizontal centerline and LR k- $\varepsilon$ for the vertical centerline. In both cases, FAC1.25 is well above the acceptance limit and very close to the aimed value $(=1)$. The SST $\mathrm{k}-\omega$ and ST $\mathrm{k}-\omega$ models do not show a good agreement along the vertical line $\left(\mathrm{U} / \mathrm{U}_{\text {in }}\right)$; FAC1.25 for both models is 0.31 , which is below the range of acceptance. Similarly, RSM shows an insufficient performance along the horizontal line $\left(\mathrm{V} / \mathrm{U}_{\text {in }}\right)$, while for the vertical line FAC1.25 is just above the range of acceptance. However, the temperatures along both lines are well reproduced by all turbulence models (e.g. FB $<0.04)$, with the best performance by the $\mathrm{k}-\omega$ models $(\mathrm{FAC} 1.05=1, \mathrm{FB}<0.02)$.

Table 4: Validation metrics for different turbulence models

\begin{tabular}{|c|c|c|c|c|c|c|}
\hline & \multirow{2}{*}{\multicolumn{2}{|c|}{$\begin{array}{c}\text { Velocity } \\
\text { FAC } 1.25\end{array}$}} & \multicolumn{4}{|c|}{ Temperature } \\
\hline & & & \multicolumn{2}{|c|}{ FAC 1.05} & \multicolumn{2}{|c|}{ FB } \\
\hline & $V / U_{\text {in }}$ & $U / U_{\text {in }}$ & horizontal & vertical & horizontal & vertical \\
\hline $\begin{array}{l}\text { Aim } \\
\text { Range }\end{array}$ & \multicolumn{2}{|c|}{$\begin{aligned} & 1 \\
> & 0.5\end{aligned}$} & \multicolumn{2}{|c|}{$\begin{array}{c}1 \\
>0.5\end{array}$} & \multicolumn{2}{|c|}{$\begin{array}{c}0 \\
(-0.3 ; 0.3) \\
\end{array}$} \\
\hline LR k- $\varepsilon$ & 0.73 & 0.92 & 0.89 & 1 & -0.03 & -0.03 \\
\hline RNG k- $\varepsilon$ & 0.91 & 0.69 & 1 & 0.89 & 0.02 & 0.03 \\
\hline SST k- $\omega$ & 0.73 & 0.31 & 1 & 1 & 0.01 & 0.02 \\
\hline ST k-w & 0.63 & 0.31 & 1 & 1 & 0.02 & 0.02 \\
\hline RSM & 0.45 & 0.69 & 0.78 & 0.67 & 0.03 & 0.04 \\
\hline
\end{tabular}

From the results, it can be concluded that in this particular case, there is no model which shows the best performance for all cases $(\mathrm{U}, \mathrm{V}, \mathrm{T})$; i.e. the $\mathrm{k}-\omega$ models perform best for temperatures, but show less good performance for velocities. Therefore, it is difficult to draw strong conclusions on the best performing turbulence model. However, overall RNG k- $\varepsilon$ model provides slightly better agreement with experimental data than other four tested models. In 
addition, it is shown that, in this particular configuration, air temperature is far less sensitive to the choice for a certain turbulence model than velocity.

\subsection{Impact of inlet velocity}

The impact of inlet velocity on the predicted dimensionless velocities and temperatures along the horizontal and vertical centerline is shown in Figure 8 . The inlet velocity is systematically changed to the values shown in Table 2 . Note that the inlet velocity $\left(U_{i n}\right)$ is increased by $25 \%$ and $50 \%$ in order to assess whether RANS is able to correctly reproduce the shift of flow direction from clockwise to anticlockwise. This behavior is observed for critical Froude number, $\mathrm{Fr}=5.31$ in the experiments and also in the LES study by Ezzhouri et al. [41].

Figure 8a,b shows the impact of the inlet velocity on $\mathrm{U} / \mathrm{U}_{\text {in }}$ and $\mathrm{V} / \mathrm{U}_{\text {in }}$ along the horizontal and the vertical centerline, respectively. Note that $U_{\text {in }}$ differs for each case, e.g. $U_{\text {in }}=0.5 U_{\text {ref }}$, etc. A very close agreement with the experimental data is present for dimensionless velocities based on an inlet velocity, which is $5 \%$ lower $\left(0.95 \mathrm{U}_{\text {ref }}\right)$ than the reference velocity $\left(U_{\text {ref }}=0.57 \mathrm{~m} / \mathrm{s}\right)$, with a mean absolute deviation up to $13.2 \%$ along the horizontal centerline. For $0.90 \mathrm{U}_{\mathrm{ref}}$, the mean average deviation is $9.8 \%$ along the vertical centerline. Figure $8 \mathrm{a}, \mathrm{b}$ shows that increasing or decreasing the inlet velocity by a range of $5-10 \%$ does not significantly influence the dimensionless velocities along both centerlines. When the reference velocity is increased by $50 \%\left(\mathrm{U}_{\mathrm{in}}=1.50 \mathrm{U}_{\text {ref }}\right)$ larger differences are present. This can be attributed to the fact that the horizontal jet has a higher momentum which results in a more downstream detachment of the wall jet from the top surface. Moreover, the jet stays attached to the inlet wall longer (Fig. 9d). When the inlet velocity is decreased by $25 \%\left(\mathrm{U}_{\text {in }}=0.75 \mathrm{U}_{\text {ref }}\right)$ and $50 \%\left(\mathrm{U}_{\text {in }}=0.50 \mathrm{U}_{\text {ref }}\right)$ the flow direction changes from clockwise to counterclockwise (Fig. 9b,c). This change can be attributed to the low momentum level of the jet. Blay et al. [42] reported a large sensitivity of the flow structure to the Froude number (Fr) and identified the existence of a critical range of Fr numbers around which the change in flow direction can be observed. This observation was also confirmed by the LES study of Ezzouhri et al. [41].

Fig. 8c,d shows the prediction of dimensionless temperatures along the horizontal $(\mathrm{y} / \mathrm{L}=$ $0.5)$ and vertical $(\mathrm{x} / \mathrm{L}=0.5)$ centerline and indicates that the temperature distribution is less sensitive to a variation of inlet velocity than the velocity distribution. When the inlet velocity changes in a range of 5-10\% compared to the reference case, the predicted temperature varies up to $2.5 \%$ along the horizontal line and up to $8.3 \%$ along the vertical centerline compared to the reference case. Compared to the experimental results the temperatures deviate with up to $4 \%$ along the horizontal line and up to $14.9 \%$ along the vertical line. For both cases of counterclockwise behavior $\left(\mathrm{U}_{\text {in }}=0.75 \mathrm{U}_{\text {ref }}\right.$ and $\left.\mathrm{U}_{\text {in }}=0.50 \mathrm{U}_{\text {ref }}\right)$, temperatures are underpredicted along the horizontal centerline $(\mathrm{y} / \mathrm{L}=0.5)$. 
a)
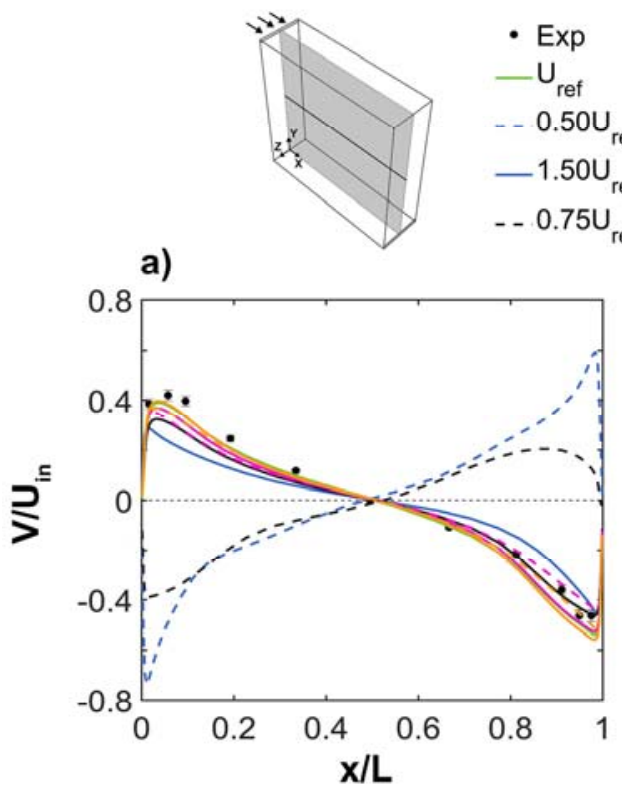

c)

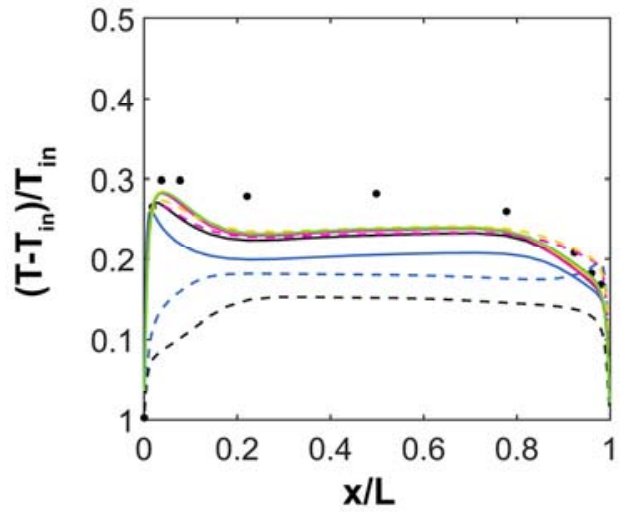

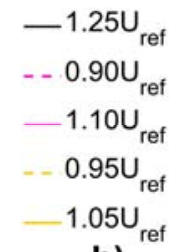

b)
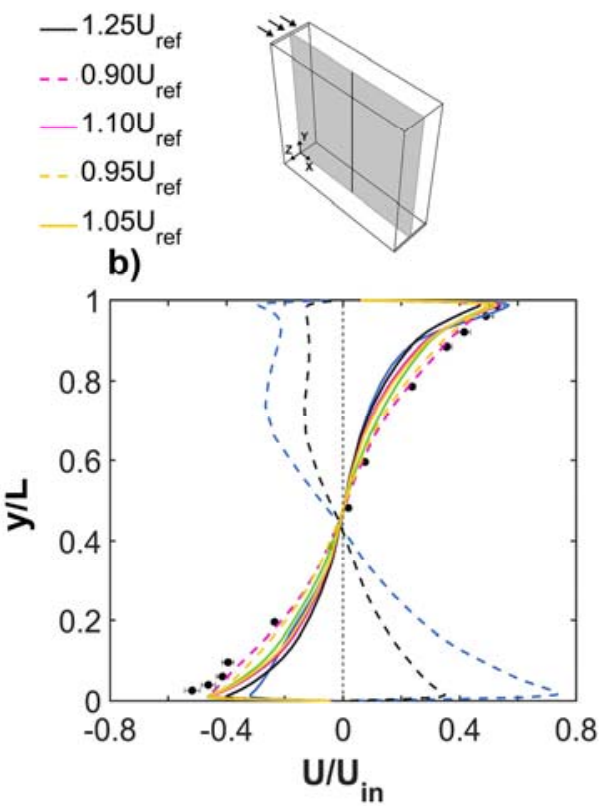

d)

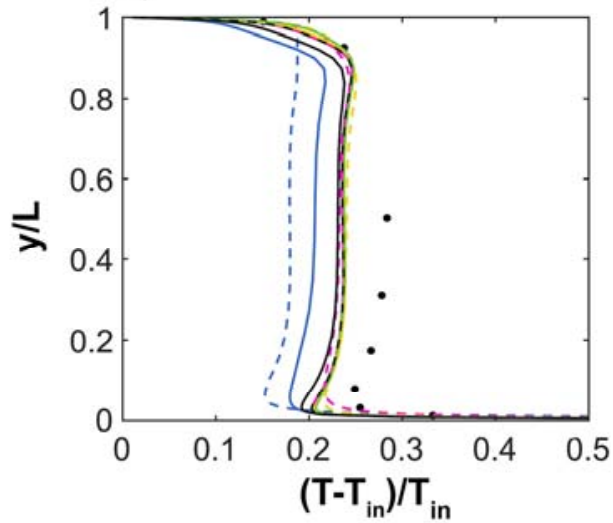

Figure 8: Results from the sensitivity analysis: impact of the inlet velocity. (a,b) $V / U_{\text {in }}$ and $U / U_{\text {in }}$ along: (a) horizontal centerline; (b) vertical centerline. $(c, d)\left(T-T_{i n}\right) / T_{\text {in }}$ along: (c) horizontal centerline; $(d)$ vertical centerline. Note that $U_{\text {in }}$ differs for each case.

Figure 9 shows contours of $|\mathrm{V}| / \mathrm{U}_{\text {ref }}$ in the vertical center plane for four different inlet velocities. Figure 9a shows the clockwise flow pattern for $U_{\text {in }}=U_{\text {ref }}=0.57 \mathrm{~m} / \mathrm{s}$. In this case, the jet is attached to the ceiling and it detaches close to the outlet wall. Figures $9 \mathrm{~b}, \mathrm{c}$ show the counterclockwise flow pattern for $\mathrm{U}_{\text {in }}=0.50 \mathrm{U}_{\text {ref }}$ and $\mathrm{U}_{\text {in }}=0.75 \mathrm{U}_{\text {ref. }}$. The jet does not attach to the ceiling due to the low momentum and it is deflected downwards and attaches to the inlet wall (left wall). Figure $9 \mathrm{~d}$ shows the velocity magnitude contours for $\mathrm{U}_{\text {in }}=1.50 \mathrm{U}_{\text {ref. }}$. The flow pattern is similar to the one depicted in Figure 9a, however, jet velocity is higher and detachment from the ceiling occurs slightly further downstream. In addition, lower dimensionless velocities are present close to the sidewalls and floor for $\mathrm{U}_{\text {in }}=1.50 \mathrm{U}_{\text {ref. }}$. 


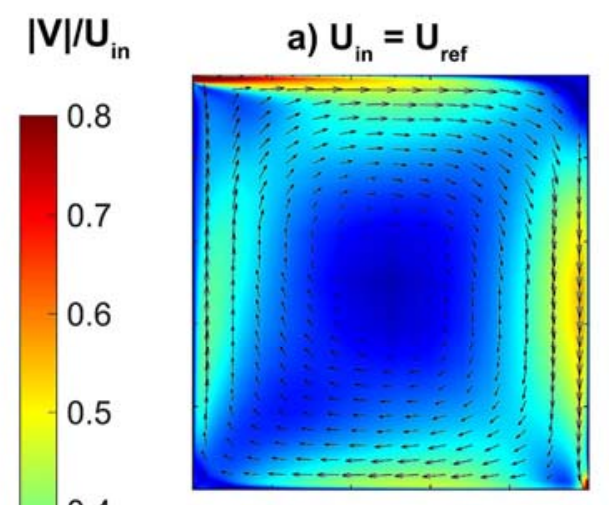

c) $U_{\text {in }}=0.75 U_{\text {ref }}$
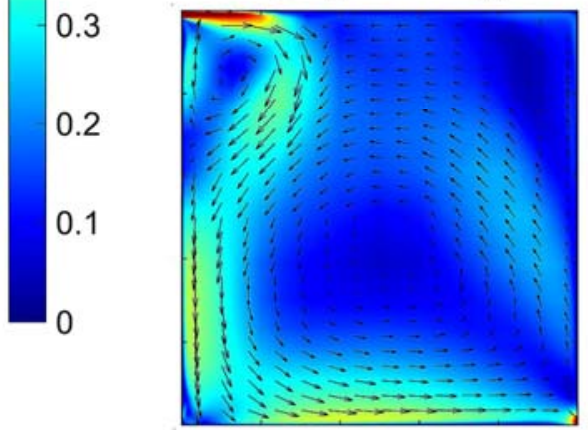

b) $U_{\text {in }}=0.50 U_{\text {ref }}$
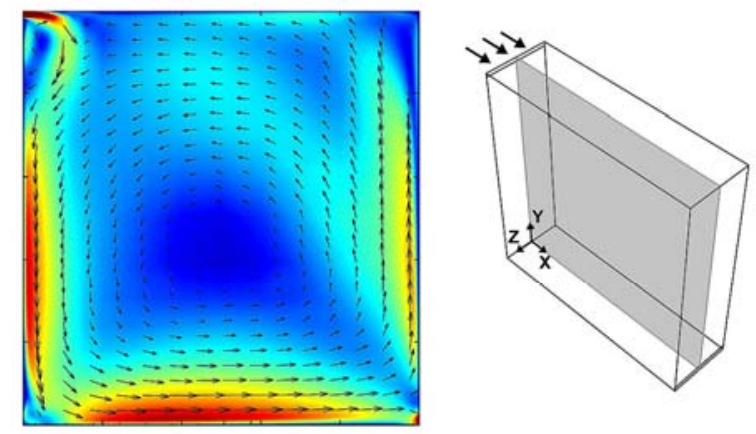

d) $U_{\text {in }}=1.50 U_{\text {ref }}$

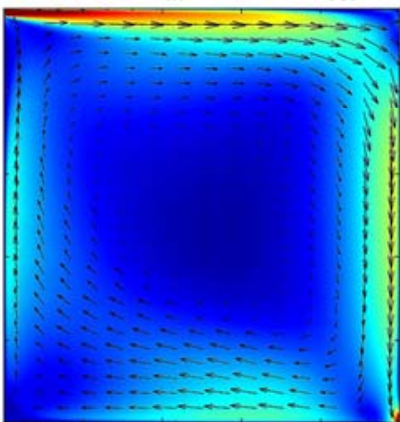

Figure 9: Velocity magnitude in a plane of analysis for different inlet velocities: (a) $U_{\text {in }}=U_{\text {ref, }}$ (b) $U_{\text {in }}=0.50 U_{\text {ref, }}$ (c) $U_{\text {in }}=0.75 U_{\text {ref, }}(d) U_{\text {in }}=1.50 U_{\text {ref; }} U_{\text {ref }}=0.57 \mathrm{~m} / \mathrm{s}$.

Table 5 summarizes the validation metrics for the different inlet velocities. Results obtained with velocities which resulted in a counter-clockwise flow pattern $\left(\mathrm{U}_{\mathrm{in}}=0.50 \mathrm{U}_{\text {ref }}\right.$ and $\mathrm{U}_{\text {in }}=$ $\left.0.75 \mathrm{U}_{\text {ref }}\right)$ fall outside the range of acceptance $(>0.5)$ for FAC1.25 (velocity). Moreover, the results obtained with a $25 \%$ and $50 \%$ higher inlet velocity $\left(\mathrm{U}_{\mathrm{in}}=1.25 \mathrm{U}_{\text {ref }}\right.$ and $\left.\mathrm{U}_{\text {in }}=1.50 \mathrm{U}_{\text {ref }}\right)$ are also out of the range of acceptance. For the temperatures, the results from $U_{\text {in }}=0.50 U_{\text {ref }}$ fall outside the range of acceptance for both lines, while for $\mathrm{U}_{\text {in }}=0.75 \mathrm{U}_{\text {ref }}$ the results are outside the range of acceptance for the horizontal line. However, the temperatures are within the range of acceptance for all inlet velocities when considering FB $(\mathrm{FB}<0.16)$. 
Table 5: Validation metrics for different inlet velocities.

\begin{tabular}{|c|c|c|c|c|c|c|}
\hline & \multirow{2}{*}{\multicolumn{2}{|c|}{$\begin{array}{l}\text { Velocity } \\
\text { FAC } 1.25\end{array}$}} & \multicolumn{4}{|c|}{ Temperature } \\
\hline & & & \multicolumn{2}{|c|}{ FAC 1.05} & \multicolumn{2}{|c|}{ FB } \\
\hline & $V / U_{\text {in }}$ & $U / U_{\text {in }}$ & horizontal & vertical & horizonta & vertical \\
\hline $\begin{array}{l}\text { Aim } \\
\text { Range }\end{array}$ & \multicolumn{2}{|c|}{$\begin{aligned} & 1 \\
&> 0.5 \\
&\end{aligned}$} & \multicolumn{2}{|c|}{$\begin{aligned} & 1 \\
&> 0.5 \\
&\end{aligned}$} & \multicolumn{2}{|c|}{$\begin{array}{c}0 \\
(-0.3 ; 0.3) \\
\end{array}$} \\
\hline$U_{\text {in }}=0.50 U_{\text {ref }}$ & 0 & 0 & 0.27 & 0.33 & 0.08 & 0.16 \\
\hline $\mathrm{U}_{\text {in }}=0.75 \mathrm{U}_{\text {ref }}$ & 0 & 0 & 0.18 & 0.88 & 0.11 & 0.01 \\
\hline$U_{\text {in }}=0.90 U_{\text {ref }}$ & 0.54 & 0.85 & 0.82 & 1 & 0.03 & 0 \\
\hline $\mathrm{U}_{\text {in }}=0.95 \mathrm{U}_{\mathrm{ref}}$ & 0.91 & 0.85 & 0.82 & 1 & 0.03 & 0.01 \\
\hline$U_{\text {in }}=U_{\text {ref }}$ & 0.91 & 0.69 & 1 & 0.89 & 0.02 & 0.03 \\
\hline $\mathrm{U}_{\mathrm{in}}=1.05 \mathrm{U}_{\mathrm{ref}}$ & 0.73 & 0.61 & 0.82 & 0.89 & 0.04 & 0.02 \\
\hline$U_{\text {in }}=1.10 U_{\text {ref }}$ & 0.82 & 0.54 & 0.82 & 1 & 0.04 & 0.01 \\
\hline $\mathrm{U}_{\text {in }}=1.25 \mathrm{U}_{\text {ref }}$ & 0.45 & 0.15 & 0.82 & 0.78 & 0.04 & 0.04 \\
\hline $\mathrm{U}_{\mathrm{in}}=1.50 \mathrm{U}_{\mathrm{ref}}$ & 0.27 & 0.31 & 0.82 & 0.11 & 0.05 & 0.02 \\
\hline
\end{tabular}

\subsection{Impact of inlet turbulent kinetic energy}

The impact of a variation of inlet turbulent kinetic energy (TKE) on the flow field is illustrated in Figure 10. The sensitivity analysis is conducted using eight different values for inlet TKE along with the reference value $\left(\mathrm{TKE}_{\text {ref }}=1.25 \cdot 10^{-3} \mathrm{~m}^{2} / \mathrm{s}^{2}\right)$. The values are depicted in Table 2 . Note that the value of inlet turbulent kinetic energy and inlet mean velocity are correlated, however, for the sake of this analysis the inlet turbulent kinetic energy and inlet velocity are artificially separated in order to investigate the effect of one independent parameter (mean velocity and then turbulent kinetic energy) on the indoor airflow. The variation of inlet TKE does not have a significant influence on the flow field; the simulation results agree well with the experimental data and show only negligible differences compared to the reference case; up to $3.7 \%$ for $0.90 \mathrm{TKE}_{\text {ref }}$ for $\mathrm{V} / \mathrm{U}_{\text {in }}$ and up to $0.7 \%$ for $1.25 \mathrm{TKE}_{\text {ref }}$ for $\mathrm{U} / \mathrm{U}_{\text {in. }}$. These findings are in line with previous studies by Saïd et al. [61] and Joubert et al. [62], however, they are also in contradiction with the results from Abdilghanie et al. [63], Cao and Meyers [64], and van Hooff and Blocken [65]. This can be attributed to the fact that the latter three studies focused on transitional inlet flow instead of fully turbulent inlet flows. Transitional inlet flows are more sensitive to the turbulence levels in the boundary layer and the amount of turbulence determines the detachment point of the wall jet in the enclosure. 
a)
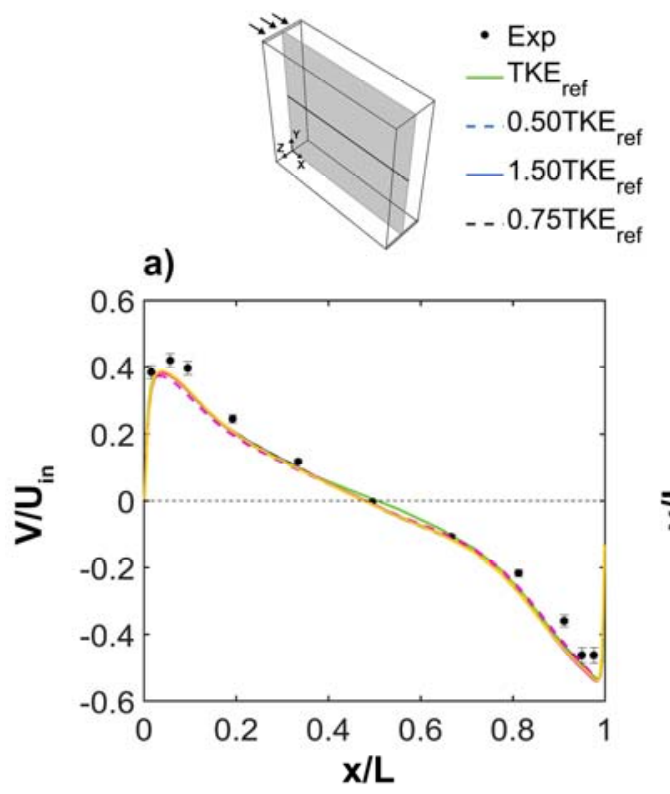

c)

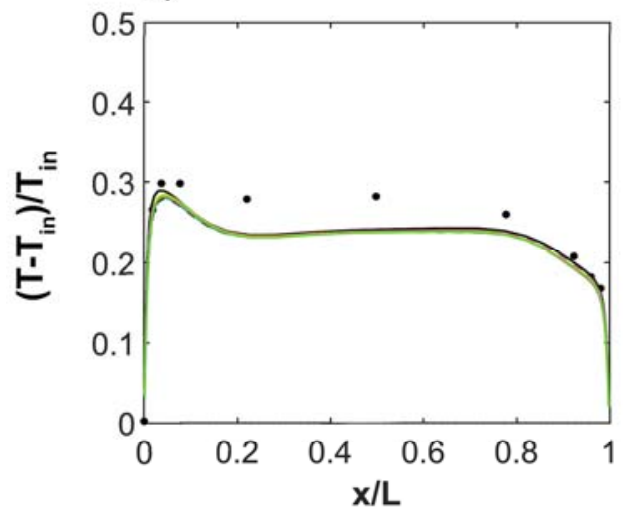

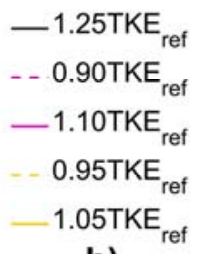

b)

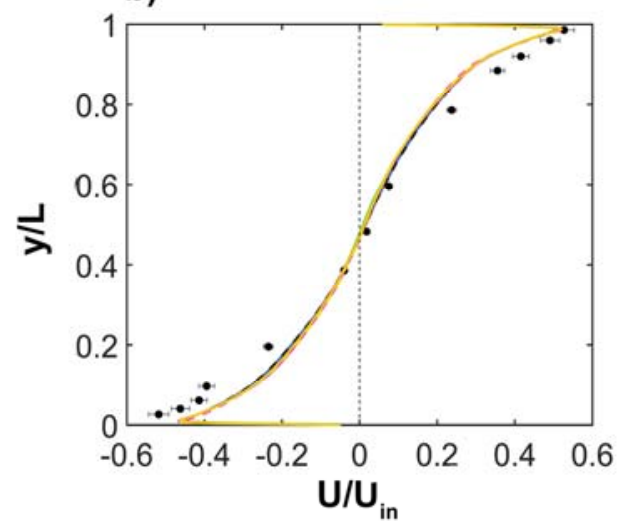

d)

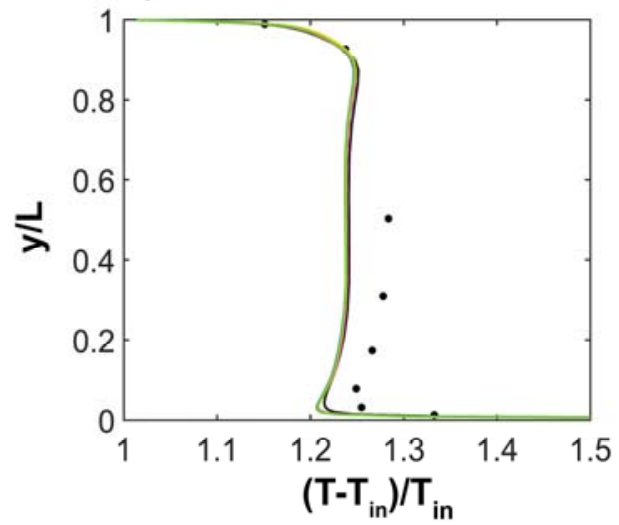

Figure 10: Results from the sensitivity analysis: impact of the inlet turbulent kinetic energy. (a, b) $V / U_{\text {in }}$ and $U / U_{\text {in }}$ along: (a) horizontal centerline; (b) vertical centerline. (c,d) $\left(T-T_{\text {in }}\right) / T_{\text {in }}$ along: (c) horizontal centerline; (d) vertical centerline.

\subsection{Impact of near-wall treatment}

The physics of the near-wall flow can be taken into account in CFD by either applying LRNM or wall functions. When using LRNM, the flow is resolved all the way down to the viscous sublayer. Wall functions, on the other hand, are semi-empirical formulae that do not resolve the viscous sublayer but rather bridge the distance between the wall and the center of the walladjacent cell. LRNM provides a higher accuracy, however, it also requires a higher near-wall grid resolution. In this section, the impact of near-wall treatment on the accuracy of the simulation is analyzed. The simulations are performed with the RNG k- $\varepsilon$ turbulence model [44] in combination with standard wall functions, scalable wall functions, and LRNM. Standard wall functions in ANSYS Fluent are based on the work of Launder and Spalding [66] and are known to deteriorate when $\mathrm{y}^{*}<11.225$, below which they typically deteriorate [43]. Although the gridresolution in the present study is too fine for the use of standard wall functions, they are used to see to which extent their improper use compromises the accuracy of the solution in this particular case. Scalable wall functions are suitable for any near-wall grid resolution, as they avoid the deterioration of standard wall functions when $\mathrm{y}^{*}<11.225$.

The maximum dimensionless wall distance $\mathrm{y}^{*}$ is equal to 5.1 along the line passing through the center of the top surface $(y / L=1 ; z / L=0.5)$ and along the line through the floor the maximum 
$\mathrm{y}^{*}$ is equal to 3.6. Figure $11 \mathrm{a}, \mathrm{b}$ shows a comparison of numerical results with experimental data for $\mathrm{V} / \mathrm{U}_{\text {in }}$ and $\mathrm{U} / \mathrm{U}_{\text {in }}$ along the horizontal and vertical centerline. The best agreement with the experimental data is achieved with LRNM, which accurately predicts the velocities along both centerlines. The results obtained using scalable wall functions do not show a good agreement with the experimental data; the velocity along the horizontal centerline is significantly underpredicted from $0<\mathrm{x} / \mathrm{L}<0.6$. As expected, standard wall functions do not accurately predict the velocities close to the inlet wall along the horizontal centerline; predicted velocities are locally up to $50 \%$ smaller than experimental values. Standard wall functions are known to deteriorate for grids with $\mathrm{y}^{*}$ below 15 [43], which is a possible explanation for the observed differences.

Fig. 11c,d shows $\left(T-T_{i n}\right) / T_{\text {in }}$ along the horizontal and vertical centerline. The temperature is well predicted along both the horizontal and vertical centerline by LRNM and standard wall functions. The use of scalable wall functions yields maximum average deviations of $2.7 \%$ for the horizontal and $4.7 \%$ for the vertical centerline.

a)

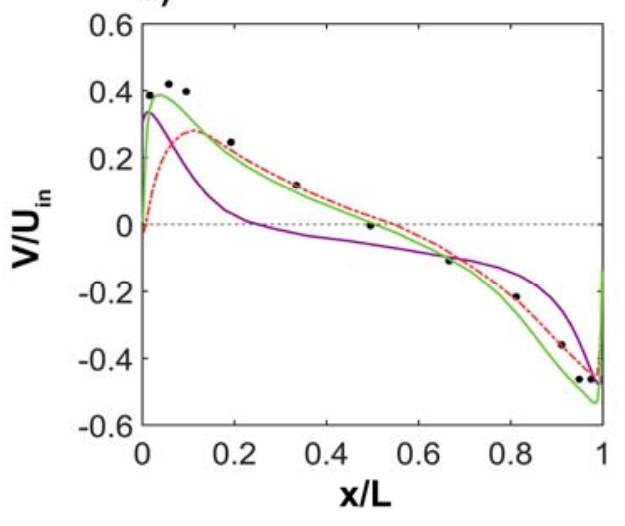

c)

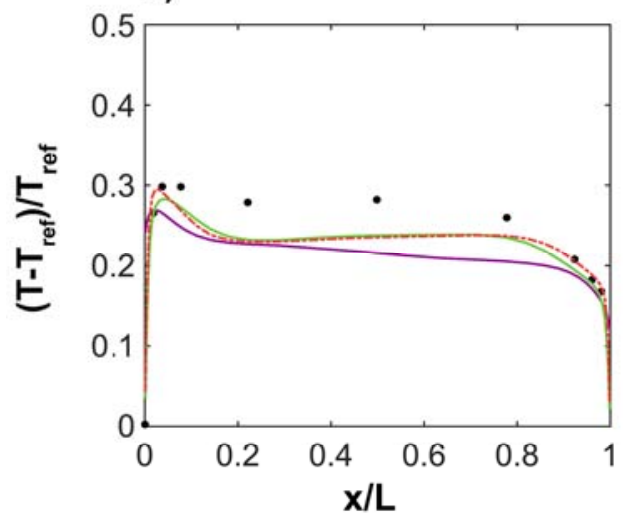

- Exp

- Scalable WF

---Standard WF

- LRNM b)
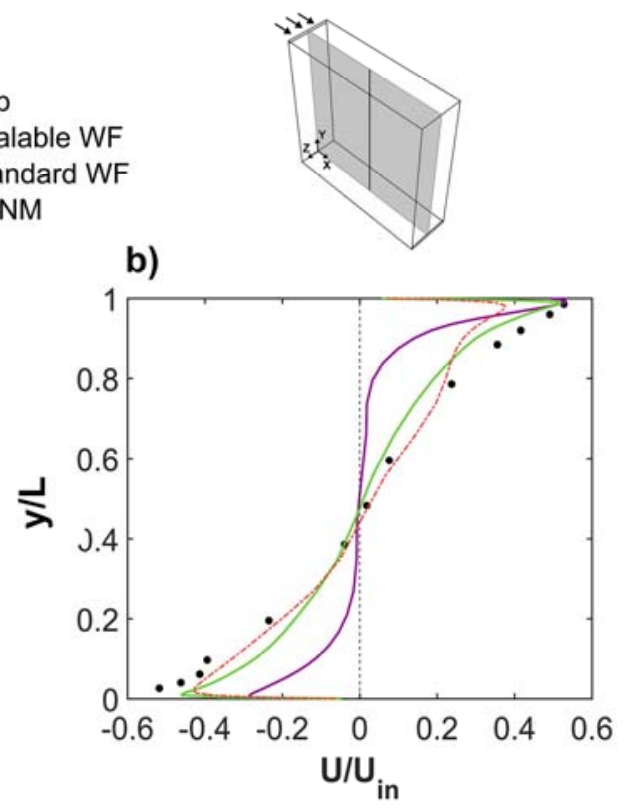

d)

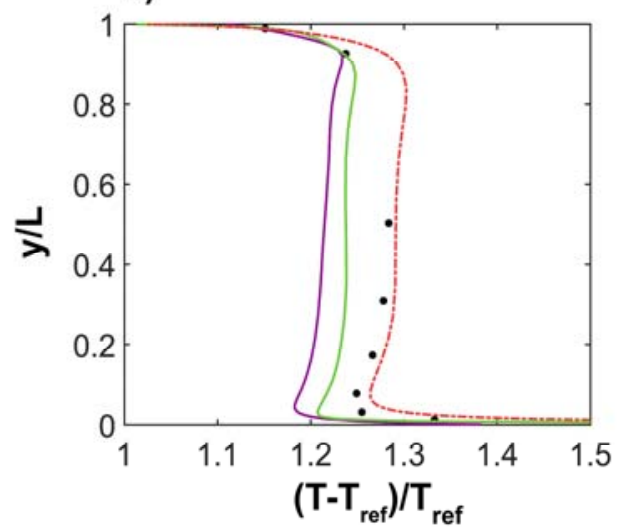

Figure 11: Results from the sensitivity analysis: impact of the near wall treatment. (a, b) $V / U_{\text {in }}$ and $U / U_{\text {in }}$ along: (a) horizontal centerline; (b) vertical centerline. (c,d) $\left(T-T_{i n}\right) / T_{\text {in }}$ along: (c) horizontal centerline; (d) vertical centerline.

The validation metrics for three different wall treatments are summarized in Table 6. LRNM shows a very good performance for velocities along the horizontal line where FAC1.25 is 0.91 , which is very close to the aimed value $(=1)$, however, the results along the vertical centerline 
are less satisfactory $(=0.69)$. Results obtained with scalable wall functions along the horizontal centerline fall outside the range of acceptance. The temperatures are predicted with sufficient accuracy for all studied near-wall treatments.

Table 6: Validation metrics for different near-wall treatment

\begin{tabular}{|c|c|c|c|c|c|c|}
\hline & \multirow{2}{*}{\multicolumn{2}{|c|}{$\begin{array}{c}\text { Velocity } \\
\text { FAC } 1.25\end{array}$}} & \multicolumn{4}{|c|}{ Temperature } \\
\hline & & & \multicolumn{2}{|c|}{ FAC 1.05} & \multicolumn{2}{|c|}{ FB } \\
\hline & $V / U_{\text {in }}$ & $\mathrm{U} / \mathrm{U}_{\text {in }}$ & horizonta & vertical & horizonta & vertical \\
\hline $\begin{array}{l}\text { Aim } \\
\text { Range }\end{array}$ & \multicolumn{2}{|c|}{$\begin{aligned} & 1 \\
&> 0.5 \\
&\end{aligned}$} & \multicolumn{2}{|c|}{$\begin{array}{c}1 \\
>0.5 \\
\end{array}$} & \multicolumn{2}{|c|}{$\begin{array}{c}0 \\
(-0.3 ; 0.3) \\
\end{array}$} \\
\hline $\begin{array}{l}\text { Enh WT } \\
\text { Stand }\end{array}$ & 0.91 & 0.69 & 1 & 0.89 & 0.02 & 0.03 \\
\hline WF & 0.64 & 0.69 & 1 & 0.89 & 0.01 & 0.04 \\
\hline Scal WF & 0.36 & 0.08 & 0.89 & 0.78 & 0.03 & -0.03 \\
\hline
\end{tabular}

WF - wall functions

\subsection{Impact of spatial discretization schemes}

In this section, the impact of spatial discretization schemes on the accuracy of the solution is analyzed. Five discretization schemes are used: first-order schemes, second-order schemes, third-order monotonic upstream-centered schemes for conservation laws (MUSCL), quadratic upstream interpolation for convective kinematics (QUICK) schemes and power-law schemes. CFD guidelines (e.g. [22, 56, 67-68]) consistently stress that first-order schemes should not be used as it introduces large diffusive errors in both streamwise and normal directions, and that at least second-order schemes are recommended.

The simulation results are shown in Figure 12. The velocity along the horizontal centerline $\left(\mathrm{V} / \mathrm{U}_{\text {in }}\right)$ is reproduced by MUSCL and QUICK schemes with a maximum absolute deviation of $14 \%$ in both cases (Fig. 12a). The discrepancies are mostly observed close to the inlet wall for QUICK schemes and close to the outlet wall for MUSCL schemes. Section 3.4 showed that second-order schemes provide a very good agreement with experimental data. The results from first-order schemes show a strong resemblance with those from power-law schemes, and both do not provide a good agreement with the experiments. The power-law schemes determine face values using an exponential profile which describes the value of the parameter as a function of horizontal location between two adjacent cell values. This profile depends on the Peclet number $(\mathrm{Pe})$, which is the ratio between convective and diffusive heat transfer in a fluid. If $\mathrm{Pe}>10$, convection dominates and the face value becomes equal to the upstream cell value, devaluating the power-law scheme to a first-order upwind scheme [43]. The Peclet number $(\mathrm{Pe}=\mathrm{Re} \times \mathrm{Pr})$ is in this case equal to 490 for $R e=684$ and Prandtl number (Pr) equal to 0.716 , and therefore the performance is very similar to that of first-order schemes. Power-law schemes and firstorder schemes significantly underpredict the velocities very close to the floor, which are up to $62.5 \%$ lower than the experimental values. Along the vertical centerline, the best performance is obtained by second-order discretization schemes with an average absolute deviation of $7 \%$, followed by QUICK schemes with an average absolute deviation of $15 \%$. Moreover, third-order MUSCL schemes provide very similar results as QUICK schemes.

Figure $12 \mathrm{c}, \mathrm{d}$ shows profiles of $\left(\mathrm{T}-\mathrm{T}_{\mathrm{in}}\right) / \mathrm{T}_{\mathrm{in}}$. In general, the predicted temperatures agree well with the measured temperatures, with a maximal average deviation of $4 \%$ for the first-order schemes. The best performance on the horizontal centerline is achieved by third-order MUSCL schemes $(1.6 \%)$ closely followed by second-order schemes $(1.9 \%)$. Similarly as for the velocities, the results from first-order schemes are almost identical to those from power-law schemes and show the worst agreement with experimental results. The best agreement along the vertical centerline (Fig. 12d) is again achieved with QUICK schemes with an average absolute deviation of $2.6 \%$. Second-order schemes and third-order MUSCL schemes also 
provide a very good estimate of temperatures along the vertical centerline, with devations of $2.9 \%$ and $2.7 \%$, respectively.

a)
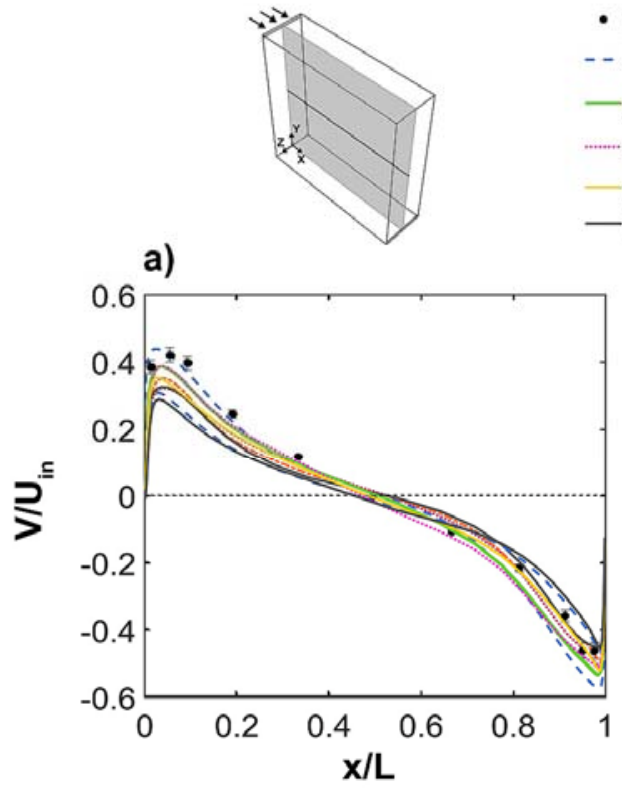

c)

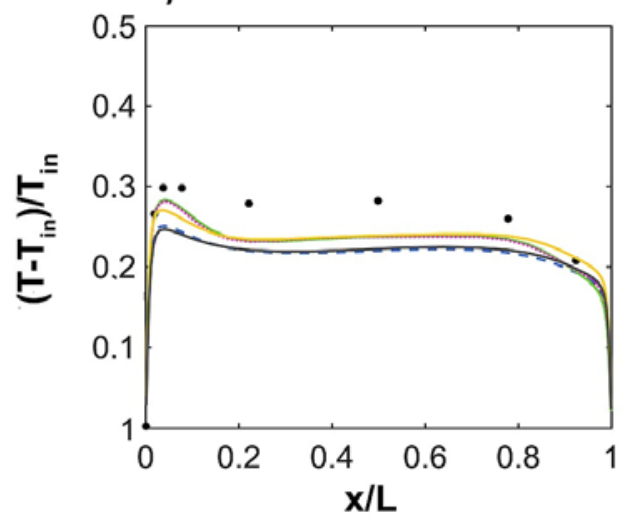

- Exp

$-1^{\text {st }}$ order

$-2^{\text {nd }}$ order

$-3^{\text {rd }}$ order

- Quick

-Power law

b)

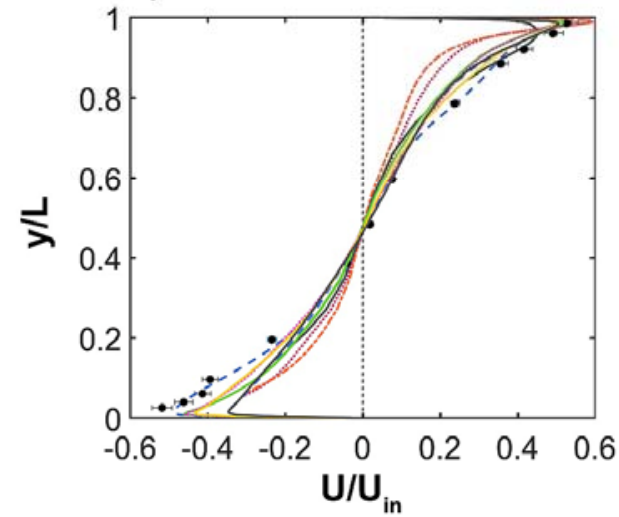

d)

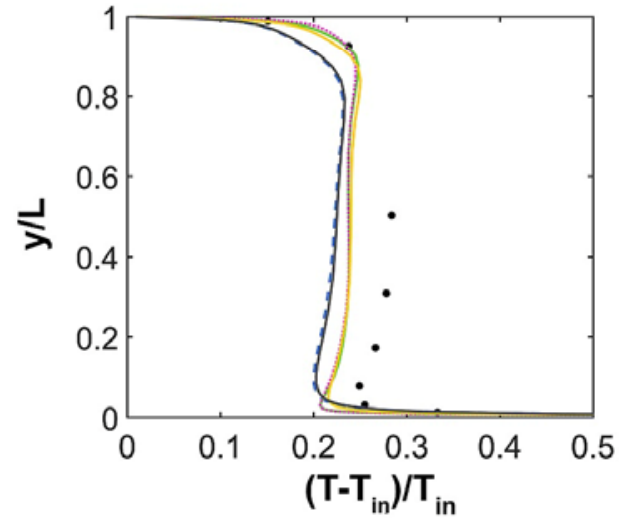

Figure 12: Results from the sensitivity analysis: impact of discretization schemes. (a, b) $V / U_{\text {in }}$ and $U / U_{\text {in }}$ along: (a) horizontal centerline; (b) vertical centerline. $(c, d)\left(T-T_{i n}\right) / T_{\text {in }}$ along: (c) horizontal centerline; (d) vertical centerline.

Table 7 summarizes the validation metrics for simulations performed with different discretization schemes. For the velocities along the horizontal centerline, the results obtained with first-order and power-law schemes are outside the range of acceptance. Validation metrics for temperature show a very good agreement between simulation results and experimental results for all analyzed discretization schemes along both centerlines. Note that FAC 1.05 for temperatures along the vertical centerline seems to indicate a better agreement with first-order than with second-order schemes. This is caused by the underprediction of temperatures very close to the floor by second-order schemes. However, in the other points along the vertical centerline the temperatures predicted by second-order schemes show a better agreement with experimental data than the first-order schemes. 
Table 7: Validation metrics for different discretization schemes.

\begin{tabular}{|c|c|c|c|c|c|c|}
\hline & \multirow{2}{*}{\multicolumn{2}{|c|}{$\begin{array}{l}\text { Velocity } \\
\text { FAC } 1.25\end{array}$}} & \multicolumn{4}{|c|}{ Temperature } \\
\hline & & & \multicolumn{2}{|c|}{ FAC 1.05} & \multicolumn{2}{|c|}{ FB } \\
\hline & $V / U_{\text {in }}$ & $U / U_{\text {in }}$ & horizontal & vertical & horizontal & vertical \\
\hline $\begin{array}{l}\text { Aim } \\
\text { Range }\end{array}$ & \multicolumn{2}{|c|}{$\begin{aligned} & 1 \\
> & 0.5\end{aligned}$} & \multicolumn{2}{|c|}{$\begin{aligned} & 1 \\
> & 0.5\end{aligned}$} & \multicolumn{2}{|c|}{$\begin{array}{c}0 \\
(-0.3 ; 0.3)\end{array}$} \\
\hline $1^{\text {st }}$ order & 0.45 & 0.62 & 1 & 1 & 0.03 & 0.03 \\
\hline $2^{\text {nd }}$ order & 0.91 & 0.69 & 1 & 0.89 & 0.02 & 0.03 \\
\hline $3^{\text {rd }}$ order MUSCL & 0.82 & 0.85 & 1 & 1 & 0.02 & -0.03 \\
\hline Power law & 0.45 & 0.62 & 1 & 1 & 0.03 & 0.03 \\
\hline Quick & 0.72 & 0.92 & 1 & 1 & 0.01 & 0.03 \\
\hline
\end{tabular}

Overall, second-order schemes, third-order MUSCL schemes and QUICK schemes all provide a very good agreement with the experimental data for both velocities and temperatures along both centerlines. However, the simulations using QUICK and MUSCL schemes show highly oscillatory behavior, therefore the results are averaged over a sufficiently large amount of iterations, 3000 in this case, which results in an increased computation time. Given the relatively small difference between the results produced by second-order schemes and QUICK and MUSCL schemes, the use of second-order schemes might be favored in this particular case.

\section{Discussion}

\subsection{Comparison with other studies}

Comparison with previous studies is not always straightforward due to the different focus, assessment criteria or different geometries used. Moreover, the presence of non-isothermal flow makes the comparison more difficult since most of the other benchmark studies were carried out for isothermal conditions. However, there are some studies of which the results can be compared with those from the present study. Ezzouhri et al [41] found a change of direction from clockwise to counterclockwise for an inlet velocity of $U_{\text {in }}=0.22 \mathrm{~m} / \mathrm{s}$ for the same cavity using LES, similar to the present study in which the velocity causing the change of direction is $\mathrm{U}_{\text {in }}=0.28 \mathrm{~m} / \mathrm{s}$.

Conclusions regarding the choice of turbulence model for a similar cavity are also not always in line with each other. For example, Costa et al. [16] and van Hooff et al. [13] reported a good agreement with experimental data using a LR number version of the k- $\varepsilon$ model, while Moureh and Flick [36] concluded that the best agreement was achieved using RSM. In the present study, the RNG k- $\varepsilon$ model provided overall slightly better agreement with experimental data than other tested models.

The effect of the inlet turbulent kinetic energy on the indoor airflow is negligible in this particular case. These conclusions are in line with findings by Said et al. [61] and Joubert et al. [62], but appear to be in contrast to the findings by Abdilghanie et al. [63], Cao and Meyers [64], and van Hooff and Blocken [65]. These apparent discrepancies can be explained by the fact that the latter three studied transitional inlet flow instead of fully turbulent inlet flows.

Regarding the impact of discretization schemes, first-order discretization schemes together with power law scheme provide the least satisfactory results, as was expected based on the knowledge from previously published CFD guidelines (e.g. [11, 22, 33, 50, 51, 67-68]).

\subsection{Limitations and future work}

The main objective of this paper is to provide a systematic analysis of the impact of six different computational and physical parameters on the results obtained by CFD simulations 
for non-isothermal mixing ventilation in a generic enclosure. The following suggestions for future research are provided:

- The study is performed for a simplified representation of the room. Future work will focus on more realistic room geometries with different opening configurations.

- The effect of computational and physical parameters on the prediction of surface heat flux is not included in the present study, due to a lack of experimental data. The correct prediction of surface heat flux is crucial for accurate modeling of convective heat transfer and ventilative cooling. Therefore, future work will also focus on the validation of heat flux predictions by CFD.

- The experimental results are provided only for the vertical and horizontal centerline and most of the points are located close to the walls. A larger data set would be beneficial for validation purposes and future work will therefore focus on obtaining more extensive experimental data sets, which can be used for the validation of non-isothermal CFD simulations.

- This sensitivity study provides valuable information on the impact of computational and physical parameters on CFD simulation results of non-isothermal mixing ventilation in a generic enclosure. The knowledge from this study can generally be used for CFD simulations of non-isothermal mixing ventilation. Note that the absolute influence of these parameters on the results obtained will always depend on the specific flow configuration and computational settings employed, and can therefore only to a certain extent be fully generalized.

- To fully generalize findings on the influence of computational and physical parameters, especially with respect to other more realistic geometries, additional detailed experiments and CFD sensitivity studies for non-isothermal indoor airflows are required.

\section{Conclusions}

Although a couple of parametric studies on non-isothermal mixing ventilation were published (e.g. [16-17, 21]), to the best knowledge of the authors, a comprehensive sensitivity study assessing the influence of computational and physical parameters on the simulation results for non-isothermal mixing ventilation has not yet been performed. Therefore, this paper presents a solution verification and validation study combined with a detailed sensitivity analysis of the impact of computational and physical parameters on the numerical results obtained by CFD for non-isothermal mixing ventilation in a generic enclosure. The 3D steady RANS simulations were validated using experimental data from literature [42]. The impact of the following computational and physical parameters was investigated: computational grid resolution, turbulence model, inlet velocity, inlet turbulent kinetic energy, near-wall treatment and spatial discretization schemes.

First, a reference case was simulated with an inlet velocity $\left(U_{\text {in }}\right)$ of $0.57 \mathrm{~m} / \mathrm{s}$, an inlet air temperature $\left(\mathrm{T}_{\mathrm{in}}\right)$ of $15^{\circ} \mathrm{C}$ and a heated floor of $\mathrm{T}_{\mathrm{fl}}=35.5^{\circ} \mathrm{C}$. The walls with inlet and outlet were kept at the same temperature as air at the inlet, i.e. $15^{\circ} \mathrm{C} .3 \mathrm{D}$ steady RANS simulations were performed with the RNG k- $\varepsilon$ turbulence model and in combination with LRNM. Secondorder discretization schemes were used for both the convective and the viscous terms of the governing equations as well as for pressure interpolation. Overall, the results showed a very good agreement with the experimental data. Subsequently, the impact of different computational and physical parameters was assessed:

- The grid-sensitivity analysis showed a small impact of the grid resolution. The results obtained from three investigated grids (coarse (= reference), medium and fine) were almost identical $(<2.6 \%$ difference) for velocities and temperatures along both the vertical $(\mathrm{x} / \mathrm{L}=0.5)$ and horizontal centerline $(\mathrm{y} / \mathrm{L}=0.5)$.

- The LR k-E model showed the best performance for the prediction of velocities (FAC1.25 > 0.73), while RSM provided an unsatisfactory performance along the 
horizontal line $(\mathrm{FAC1} 1.25=0.45)$ and SST k- $\omega$ and ST k- $\omega$ along the vertical line (FAC1.25 $=0.31$ for both). The temperatures were most accurately reproduced by the SST k- $\omega$ model $(\mathrm{FAC1} 1.05=1, \mathrm{FB}<0.02)$, however, the rest of the models also showed a very satisfactory agreement with the experimental data for temperatures (e.g. FB $<$ $0.04)$.

- The influence of the inlet velocity on the flow field was possibly very large. Inlet velocities of $\mathrm{U}_{\text {in }}=0.75 \mathrm{U}_{\text {ref }}$ and $\mathrm{U}_{\text {in }}=0.50 \mathrm{U}_{\text {ref }}$ changed the flow direction from clockwise to counter-clockwise due to the low momentum level of the jet. Temperatures were generally well predicted, except for the cases in which the flow direction changed $\left(0.50 \mathrm{U}_{\text {ref; }} 0.75 \mathrm{U}_{\text {ref }}\right)$.

- The variation of inlet turbulent kinetic energy showed negligible impact on the accuracy of the results.

- LRNM showed the best agreement with experimental data; FAC1.25 $>0.69$ for velocities, and FAC1.05 $>0.89$ and $\mathrm{FB}<0.03$ for temperatures, while scalable wall functions did not provide a good agreement in terms of velocities, which were up to two times smaller than the measured data.

- The power-law discretization schemes provided results very similar to those by the first-order schemes. Third-order MUSCL schemes provided very similar results to those obtained with second-order schemes along the horizontal centerline for both velocities and temperatures. QUICK showed a slightly worse performance than second-order and MUSCL schemes along the horizontal centerline for velocities, as well as for temperatures, but provided almost identical results to those obtained with second-order and MUSCL schemes for the velocity along the vertical centerline. However, both, MUSCL and QUICK schemes showed highly oscillatory behavior and therefore the use of second-order schemes might be favored.

\section{Acknowledgements}

Twan van Hooff is currently a postdoctoral fellow of the Research Foundation - Flanders (FWO) and acknowledges its financial support (project FWO 12R9715N; FWO 12R9718N). In addition, the authors gratefully acknowledge the partnership with ANSYS CFD.

\section{References}

[1] M. P. Straw, C. J. Baker, and A. P. Robertson, "Experimental measurements and computations of the wind-induced ventilation of a cubic structure”, J. Wind. Eng. Ind. Aerodyn., vol. 88, no. 2-3, pp. 213-230, 2000 .

[2] A. Tecle, G. T. Bitsuamlak, and T. E. Jiru, "Wind-driven natural ventilation in a low-rise building: A boundary layer wind tunnel study", Build. Environ., vol. 59, pp. 275-289, 2013.

[3] P. Karava, T. Stathopoulos, and A. K. Athienitis "Airflow assessment in cross-ventilated buildings with operable facade elements", Build. Environ., vol. 59, pp. 266 - 279, 2011

[4] G. R. Hunt and P. P. Linden, "The fluid mechanics of natural ventilation-displacement ventilation by buoyancy-driven flows assisted by wind”, Build. Environ., vol. 34, no. 6, pp. 707-720, 1999.

[5] S. Kato, S. Murakami, A. Mochida, S. Akabayashi, and Y. Tominaga, "Velocity-pressure field of cross ventilation with open windows analyzed by wind tunnel and numerical simulation," J. Wind Eng. Ind. Aerodyn., vol. 44, no. 1-3, pp. 2575-2586, 1992.

[6] T. van Hooff and B. Blocken, "Full-scale measurements of indoor environmental conditions and natural ventilation in a large semi-enclosed stadium: possibilities and limitations for CFD validation", $J$. Wind Eng. Ind. Aerodyn., vol. 104-106, pp. 330-341, 2012.

[7] C. J. Coffey and G. R. Hunt, "Ventilation effectiveness measures based on heat removal: part 2. Application to natural ventilation flows", Build. Environ., vol. 42, no. 6, pp. 2249-2262, 2007.

[8] T. S. Larsen and P. Heiselberg, "Single-sided natural ventilation driven by wind pressure and temperature difference”, Energy Build., vol. 40, no. 6, pp. 1031-1040, 2008.

[9] M. Z. I Bangalee, J. J. Miau, S.Y. Lin, J. H. Yang, "Flow visualization, PIV measurement and CFD calculation for fluid-driven natural cross-ventilation in a scale model”, Energy Build., vol 66, pp. 306-314, 
2013.

[10] M. J. Cook, Y. Ji, G. R. Hunt, "CFD modeling of natural ventilation: Combined wind and buoyancy forces”, Int. J. Vent., vol 1, no. 3, pp. 169-179, 2003

[11] R. Ramponi and B. Blocken, "CFD simulation of cross-ventilation flow for different isolated building configurations: Validation with wind tunnel measurements and analysis of physical and numerical diffusion effects," J. Wind Eng. Ind. Aerodyn.", vol. 104-106, pp. 408-418, 2012.

[12] T. van Hooff and B. Blocken, "Coupled urban wind flow and indoor natural ventilation modelling on a high-resolution grid: A case study for the Amsterdam ArenA stadium”, Environ. Model. Softw., vol. 25, no. 1, pp. 51-65, 2010.

[13] T. van Hooff, B. Blocken, and G. J. F. van Heijst, "On the suitability of steady RANS CFD for forced mixing ventilation at transitional slot Reynolds numbers”, Indoor Air, vol. 23, no. 3, pp. 236-249, 2013.

[14] M. Z. I. Bangalee, S. Y. Lin, and J. J. Miau, "Wind driven natural ventilation through multiple windows of a building: A computational approach”, Energy Build., vol. 45, pp. 317-325, 2012.

[15] J. Moureh and D. Flick, "Wall air-jet characteristics and airflow patterns within a slot ventilated enclosure", Int. J. Therm. Sci., vol. 42, no. 7, pp. 703-711, 2003.

[16] J. J. Costa, L. A. Oliveira, and D. Blay, "Test of several versions for the k- $\varepsilon$ type turbulence modelling of internal mixed convection flows", Int. J. Heat Mass Transf., vol. 42, no. 23, pp. 4391-4409, 1999.

[17] J. J. Costa, L. A. Oliveira, and D. Blay, "Turbulent airflow in a room with a two-jet heating-ventilation system - A numerical parametric study”, Energy Build., vol. 32, no. 3, pp. 327-343, 2000.

[18] S. Hussain and P. H. Oosthuizen, "Numerical study of buoyancy-driven natural ventilation in a simple three-storey atrium building”, Int. J. Sustain. Built Environ., vol. 1, no. 2, pp. 141-157, 2012.

[19] J. O. P. Cheung and C.-H. Liu, "CFD simulations of natural ventilation behaviour in high-rise buildings in regular and staggered arrangements at various spacings", Energy Build., vol. 43, no. 5, pp. 1149-1158, 2011.

[20] G. C. Graca, Q. Chen, L. R. Glicksman, and L. K. Norford, "Simulation of wind-driven ventilative cooling systems for an apartment building in Beijing and Shanghai", Energy Build., vol. 34, no. 1, pp. 1-11, 2002.

[21] E. Pulat and H. A. Ersan, "Numerical simulation of turbulent airflow in a ventilated room: Inlet turbulence parameters and solution multiplicity", Energy Build., vol. 93, pp. 227-235, 2015.

[22] P.V. Nielsen, "Computational fluid dynamics and room air movement”, Indoor Air, vol. 14, pp. 134 - 143, 2014.

[23] Y. Jiang, D. Alexander, H. Jenkins, R. Arthur, and Q. Chen, "Natural ventilation in buildings: Measurement in a wind tunnel and numerical simulation with large-eddy simulation", J. Wind Eng. Ind. Aerodyn., vol. 91, no. 3, pp. 331-353, 2003.

[24] C.-H. Hu, M. Ohba, and R. Yoshie, "CFD modelling of unsteady cross ventilation flows using LES", $J$. Wind Eng. Ind. Aerodyn., vol. 96, no. 10-11, pp. 1692-1706, 2008.

[25] Q. Chen, "Prediction of room air motion by Reynolds-stress models", Build. Environ., vol. 31, no. 3, pp. 233-244, 1996.

[26] G. M. Stavrakakis, M. K. Koukou, M. G. Vrachopoulos, and N. C. Markatos, "Natural cross-ventilation in buildings: Building-scale experiments, numerical simulation and thermal comfort evaluation", Energy Build., vol. 40, no. 9, pp. 1666-1681, 2008.

[27] R. M. Susin, G. A. Lindner, V. C. Mariani, and K. C. Mendonça, "Evaluating the influence of the width of inlet slot on the prediction of indoor airflow: Comparison with experimental data", Build. Environ., vol. 44, no. 5, pp. 971-986, 2009.

[28] T. van Hooff and B. Blocken, "CFD evaluation of natural ventilation of indoor environments by the concentration decay method: $\mathrm{CO} 2$ gas dispersion from a semi-enclosed stadium”, Build. Environ., vol. 61, pp. 1-17, 2013.

[29] S. Gilani, H. Montazeri, and B. Blocken, "CFD simulation of stratified indoor environment in displacement ventilation: Validation and sensitivity analysis”, Build. Environ., vol. 95, pp. 299-313, 2016.

[30] T. van Hooff, B. Blocken, and Y. Tominaga, "On the accuracy of CFD simulations of cross-ventilation flows for a generic isolated building: Comparison of RANS, LES and experiments", Build. Environ., vol. 114, pp. 148-165, 2017.

[31] F. Durrani, M. J. Cook, and J. J. McGuirk, "Evaluation of LES and RANS CFD modelling of multiple steady states in natural ventilation”, Build. Environ., vol. 92, pp. 167-181, 2015.

[32] S. Murakami, A. Mochida, and Y. Hayashi, "Examining the k- $\varepsilon$ model by means of a wind tunnel test and large-eddy simulation of the turbulence structure around a cube", J. Wind Eng. Ind. Aerodyn., vol. 35, pp. 87-100, 1990. 
[33] R. Ramponi and B. Blocken, "CFD simulation of cross-ventilation for a generic isolated building: Impact of computational parameters", Build. Environ., vol. 53, pp. 34-48, 2012.

[34] J. I. Perén, T. van Hooff, B. C. C. Leite, and B. Blocken, "CFD analysis of cross-ventilation of a generic isolated building with asymmetric opening positions: Impact of roof angle and opening location", Build. Environ., vol. 85, pp. 263-276, 2015.

[35] Q. Chen, "Comparison of different k- $\varepsilon$ models for indoor air flow computations", Numer. Heat Transf. Part B Fundam., vol. 28, no. 3, pp. 353-369, 1995.

[36] J. Moureh and D. Flick, "Airflow characteristics within a slot-ventilated enclosure”, Int. J. Heat Fluid Flow, vol. 26, no. 1, pp. 12-24, 2005.

[37] C. C. Chieng and B. E. Launder, "On the calculation of turbulent heat transport downstream from an abrupt pipe expansion”, Numer. Heat Transf., vol. 3, no. 2, pp. 189-207, 1980.

[38] M. Wolfshtein, "The velocity and temperature distribution in one-dimensional flow with turbulence augmentation and pressure gradient”, Int. J. Heat Mass Transf., vol. 12, no. 3, pp. 301-318, 1969.

[39] Y. Nagano and M. Hishida, "Improved form of the k- $\varepsilon$ model for wall turbulent shear flows", J. Fluids Eng., vol. 109, no. 2, pp. 156-160, 1987.

[40] K. Hanjalić, “Advanced turbulence closure models: a view of current status and future prospects", Int. J. Heat Fluid Flow, vol. 15, no. 3, pp. 178-203, 1994.

[41] R. Ezzouhri, P. Joubert, F. Penot, and S. Mergui, "Large eddy simulation of turbulent mixed convection in a 3D ventilated cavity: Comparison with existing data”, Int. J. Therm. Sci., vol. 48, no. 11, pp. 2017-2024, 2009.

[42] D. Blay, S. Mergui, and C. Niculae, "Confined turbulent mixed convection in the presence of a horizontal buoyant wall jet”, Fundam. Mix. Convect. ASME, vol. 213, pp. 65-72, 1992.

[43] ANSYS Inc, ANSYS Fluent theory guide, Canonsburg, PA, 2013

[44] V. Yakhot, S. A. Orszag, S. Thangam, T. B. Gatski, and C. G. Speziale, "Development of turbulence models for shear flows by a double expansion technique", Phys. Fluids A Fluid Dyn., vol. 4, no. 7, p. $1510,1992$.

[45] L. Peng, P.V. Nielsen, X. Wang, S. Sadrizadeh, L. Liu, and Y. Li, “ Possible user-dependent CFD predictions of transitional flow in building ventilation", Build. Environ., vol. 99, pp. 130-141, 2016.

[46] J. D. Posner, C. R. Buchanan, and D. Dunn-Rankin, “ Measurements and prediction of indoor airflow in a model room”, Energy Build., vol. 35, no. 5, pp. 515-526, 2003.

[47] G. Gan, "Prediction of turbulent buoyant flow using an RNG k-e model," Numer. Heat Transf. Part A. Appl., vol. 33, no.2, pp. 169-189, 1998.

[48] Q. Chen and J. Srebric, "A procedure for verification, validation and reportings of indoor environment CFD analyses”, HVAC\&R Res., vol.8, no.2, pp. 201-216, 2002.

[49] M. Casey, and T. Wintergerste, "Best practice guidelines, ERCOFTAC special interest group on quality and trust in industrial CFD”, Brussels, 2000.

[50] B. Blocken, “ Computational fluid dynamics for urban physics: Importance, scales, possibilities, limitations and ten tips and tricks towards accurate and reliable simulations", Build. Environ.,vol. 91, pp. 219-245, 2015.

[51] P.J Roache, “Perspecitve - method for uniform reporting of grid refinement studies", ASME, J. Fluids Eng., vol. 116 (3), pp. 405-413, 1994.

[52] P.J. Roache, "Quantification of uncertainty in computational fluid dynamics." Annu. Rev. Fluid Mech, vol. 29, pp.123-160, 1997.

[53] J.H. Ferziger, M. Peric, Computational methods for fluid dynamics .Third edition, Springer, Berlin, Heidelberg, New York, 2002.

[54] J. Franke, C. Hirsch, A.G. Jensen, H.W. Krus, M. Schatzmann, P.S. Westbury, S. D. Miles, J. A. Wisse, N. G. Wright, " Recommendations on the use of CFD in wind engineering”, In: J.P.A.J van Beeck, (Ed.), Proceedings of the International Conference on Urban Wind Engineering and Building Aerodynamics. COST Action C14, Impact of Wind and Storm on City Life Built Environment, Von Karman Insitute, SintGenesius-Rode, Belgium, 5-7 May, 2004.

[55] Y. Tominaga, A. Mochida, R. Yoshie, H. Kataoka, T. Nozu, M. Yoshikawa, T. Shirasawa. "AIJ guidelines for practical applications of CFD to pedestrian wind environment around buildings." J. Wind. Eng. Ind. Aerodyn., vol. 96 (10-11), pp. 1749-1761, 2008.

[56] J. F. Schatzman, H. Olesen and J. Franke, "COST 732 Model evaluation case studies: Approach and results", 2010. 
[57] B. E. Launder and N. Shima, "Second-moment closure for the near-wall sublayer: Development and application,” AIAA Journal, vol. 27, no. 10, pp. 1319-1325, 1989.

[58] R. Abid, "Evaluation of two-equation turbulence models for predicting transitional flows", Int. J. Eng. Sci., vol. 31, no. 6, 1993.

[59] F. R. Menter, "Two-equation eddy-viscosity turbulence models for engineering applications", AIAA J., vol. 32, no. 8, pp. 1598-1605, 1994.

[60] D. C. Wilcox, Turbulence modeling for CFD. La Canada CA, DCW Industries, 1998.

[61] M. N. A. Said, D. B. Jouini, and E. G. Plett, "Influence of turbulence parameters at supply inlet on room air diffusion", in Proc. ASME Winter Meeting, Paper 93-WA/HT-67, p. 14, 1993.

[62 P. Joubert, A. Sandu, C. Beghein, F. Allard "Numerical study of the influence of inlet boundary conditions on the air movement in a ventilated enclosure", in In Proceedings of the Roomvent, 1996, pp. 235-242, 1996

[63] A. M. Abdilghanie, L. R. Collins, and D. A. Caughey, "Comparison of Turbulence Modeling Strategies for Indoor Flows", J. Fluids Eng., vol. 131, no. 5, pp 2 - 18, 2009.

[64] S. J. Cao and J. Meyers, "Influence of turbulent boundary conditions on RANS simulations of pollutant dispersion in mechanically ventilated enclosures with transitional slot Reynolds number”, Build. Environ., vol. 59, pp. 397-407, 2013.

[65] T. van Hooff and B. Blocken, "The influence of physical and numerical diffusion on the flow field and contaminant distribution for low-Reynolds number mixing ventilation flows", Build. Simul., vol. 10, pp. 589-606, 2017.

[66] B.E Launder and D.B Spalding, "The numerical computations of turbulent flow", Comput. Methods Appl. Mech. Eng., vol. 3, no. 2, pp. 269-289, 1974.

[67] P. V. Nielsen, F. Allard, H. B. Awbi, L. Davidson, and A. Schalin, REHVA Guidebook No 10: Computational Fluid Dynamics in Ventilation Design, Forssa, Finland: REHVA, 2007.

[68] D. N. Sørensen and P. V. Nielsen, "Quality control of computational fluid dynamics in indoor environments", Indoor Air, vol. 13, no. 1, pp. 2-17, 2003. 